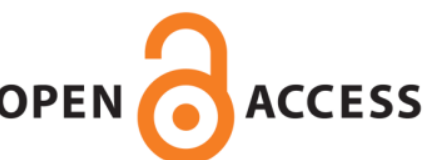

UWS Academic Portal

\title{
Ethical considerations in fish research
}

Sloman, K.A.; Bouyoucos, I.A.; Brooks, E.J.; Sneddon, L.U.

Published in:

Journal of Fish Biology

DOI:

$10.1111 / \mathrm{jfb} .13946$

Published: 11/04/2019

Document Version

Peer reviewed version

Link to publication on the UWS Academic Portal

Citation for published version (APA):

Sloman, K. A., Bouyoucos, I. A., Brooks, E. J., \& Sneddon, L. U. (2019). Ethical considerations in fish research. Journal of Fish Biology, 94(4), 556-577. [13946]. https://doi.org/10.1111/jfb.13946

\section{General rights}

Copyright and moral rights for the publications made accessible in the UWS Academic Portal are retained by the authors and/or other copyright owners and it is a condition of accessing publications that users recognise and abide by the legal requirements associated with these rights.

Take down policy

If you believe that this document breaches copyright please contact pure@uws.ac.uk providing details, and we will remove access to the work immediately and investigate your claim. 
"This is the peer reviewed version of the following article: Sloman, K. A., Bouyoucos, I. A., Brooks, E. J., \& Sneddon, L. U. (2019). Ethical considerations in fish research. Journal of Fish Biology., which has been published in final form at https://doi.org/10.1111/jfb.13946. This article may be used for non-commercial purposes in accordance with Wiley Terms and Conditions for Use of SelfArchived Versions."

https://authorservices.wiley.com/author-resources/Journal-Authors/licensing/self-archiving.html 


\section{Ethical Considerations in Fish Research}

4 Sloman, K.A. ${ }^{1}$, Bouyoucos, I.A. ${ }^{2,3}$, Brooks, E.J. ${ }^{4} \&$ Sneddon, L.U. ${ }^{5}$

5

6

$7 \quad{ }^{1}$ School of Health and Life Sciences, University of the West of Scotland, Paisley PA1 2BE

$8 \quad{ }^{2}$ Australian Research Council Centre of Excellence for Coral Reef Studies, James Cook

9 University, Townsville, Queensland, 4811, Australia

$10{ }^{3}$ PSL Research University, EPHE-UPVD-CNRS, USR 3278 CRIOBE, Université de 11 Perpignan, 58 Avenue Paul Alduy, 66860 Perpignan Cedex, France

$12{ }^{4}$ Cape Eleuthera Island School, Rock Sound, Eleuthera, The Bahamas

$13{ }^{5}$ Institute of Integrative Biology, University of Liverpool, Liverpool L69 7ZB 
Abstract

Fishes are used in a wide range of scientific studies, from conservation research with potential benefits to the species used to biomedical research with potential human benefits. Fish research can take place in both laboratories and field environments and methods used represent a continuum from non-invasive observations, handling, through to experimental manipulation. While some countries have legislation or guidance regarding the use of fish in research, many do not and there exists a diversity of scientific opinions on the sentience of fish and how we determine welfare. Nevertheless, there is a growing pressure on the scientific community to take more responsibility for the animals they work with through maximising the benefits of their research to humans or animals while minimising welfare or survival costs to their study animals. In this review, we focus primarily on the refinement of common methods used in fish research based on emerging knowledge with the aim of improving the welfare of fish used in scientific studies. We consider the use of anaesthetics and analgesics, and how we mark individuals for identification purposes. We highlight the main ethical concerns facing researchers in both laboratory and field environments and identify areas which need urgent future research. We hope that this review will help inform those who wish to refine their ethical practices and stimulate thought among fish researchers for further avenues of refinement. Improved ethics and welfare of fishes will inevitably lead to increased scientific rigour and is in the best interests of both fishes and scientists. 
Fish Welfare

41

The application of animal welfare concepts to fishes has lagged behind that of mammals.

However, fish welfare has received a considerable amount of attention in recent years, both in relation to research and to commercial practices such as aquaculture and the ornamental fish trade. The definition of 'welfare' will almost certainly depend on an individual researcher's contemplation but can be approached from three perspectives (Huntingford et al., 2006), which are feelings-based, function-based or nature-based. Good welfare from a feelingsbased perspective means that the animal should feel well, and should be free from pain or fear, and have access to positive experiences. From a function-based perspective, an animal should be in good health and be in an environment that does not require it to function beyond its capacity. Nature-based good welfare requires that an animal can lead a natural life and express natural behaviour. Previous reviews on fish welfare have adopted feelings-based (Huntingford et al., 2006) and function-based (Arlinghaus et al., 2007) approaches. Despite conflict between these attitudes, under many circumstances they may come to the same conclusions regarding the best approaches to fish welfare. One of the key controversies in the field of fish welfare is whether or not fishes experience pain (Sneddon, 2015). While acceptance or rejection of the idea that fishes are sentient animals may influence a researcher's use of some welfare refinements (e.g. analgesia), opportunities to improve fish welfare can often be justified regardless of a researcher's stance on fish pain (Browman et al., 2018). Therefore, the aim of this review is to bring together existing information on fish welfare to allow the reader to make informed decisions around the methods used in fish research. In many countries there is legislation or guidance surrounding the use of fishes in scientific research, but for many countries no guidelines exist. As scientists we have a moral responsibility to consider the impacts of our research methods from a variety of perspectives including the impact on the individual animal and implications for its natural environment, while also ensuring that the best scientific methods for validity of results are used. 
Huntingford et al. (2006). These state that animals should be free from (1) water and food deprivation, malnutrition; (2) environmental challenge; (3) disease, injury and functional impairment; (4) behavioural/interactive restriction and (5) mental and physical suffering. Some of these freedoms are intuitive and easy to interpret, such as the avoidance of disease and injury. However, others such as freedom from environmental challenge, or from mental suffering are more difficult to interpret. If we are to refine scientific methods of working with fishes to improve welfare then it is necessary to know how to assess fish welfare.

The natural stress response of fishes is often used in our assessment of welfare (Conte, 2004; Sneddon et al., 2016) not least because our understanding of the physiological response of fishes to a variety of stressors is extensive, with many books and reviews written on the subject (e.g. Iwama et al., 1997; Schreck, 2000; Barton, 2002; Schreck et al., 2016). However, we cannot assume that there is always a direct relationship between stress and welfare. For example, there are instances when physiological stress may be beneficial (Mommsen et al., 1999; Love et al., 2013; eustress, Schreck \& Tort, 2016) and examples of adverse conditions that do not cause measureable activation of the stress axis (Huntingford $e t$ al., 2006; Schreck \& Tort, 2016).

Behaviour, or behavioural deficits are often used in the assessment of animal welfare (Mench \& Mason, 1997) including choice tests (Dawkins, 1998, 2004), although these are based on the assumption that the animal will choose what is best for its own welfare which may not necessarily be the case. In fishes, a variety of welfare indicators have been suggested including changes in colour, ventilation rate, swimming behaviour, reduced food intake, loss of condition, slow growth, morphological abnormalities, injury, disease outbreaks and reduced reproductive output (Huntingford et al., 2006; Sneddon et al., 2016; Wilson et al., 2018). In reality, combined measures are likely to be the best way of assessing welfare (Huntingford et al., 2006) to account for intra-and inter-individual variation in specific responses (Mason \& Mendl, 1993).

Legislation and Guidelines

Concern for fish welfare has led to legislation and guidance in some countries and the adoption of ethical guidelines by some scientific journals. While some countries have their 
own extensive guidance documents for the use of animals in research (e.g. Canada:

http://www.ccac.ca/; USA: https://grants.nih.gov/grants/olaw/guide-for-the-care-and-use-oflaboratory-animals.pdf; Australia: https://nhmrc.gov.au/about-us/publications/australiancode-care-and-use-animals-scientific-purposes) or legislation (UK:

http://www.homeoffice.gov.uk/science-research/animal-research/; EU: https://eurlex.europa.eu/legal-content/EN/TXT/?uri=CELEX:32010L0063), it should be recognised that a large number of countries do not have such guidance. As well as legislation surrounding experimentation on animals, working with fishes, particularly in the field, may require permits to work and sample fishes. It should also be recognised that just because something is permitted, or not mentioned, within such guidelines and legislation does not automatically make it ethical. Therefore, there is an onus on the individual researcher and research group to assess the ethics of their research based on our current understanding of fish biology, and to update this as knowledge changes. There are many guidance documents written for those working with animals used for scientific purposes, some of which are specifically tailored for fish. Examples include Guidelines for the treatment of animals in behavioural research and teaching, published by the journal Animal Behaviour (ASAB, 2012, 2018), Ethical justification for the use and treatment of fishes in research (Journal of Fish Biology, 2006; Metcalfe \& Craig, 2011) published by the Journal of Fish Biology and Guidelines for the use of fishes in research (AFS, 2014) published by the American Fisheries Society. In 2010 the ARRIVE (Animal Research: Reporting of In Vivo Experiments) guidelines were published as part of the National Centre for the Replacement, Refinement and Reduction of Animal Research (NC3Rs) in PLoS Biology, although these focus more on experimental design and reporting of experiments involving laboratory animals rather than specific welfare issues (Kilkenny et al., 2010). Recently (2017), the complimentary PREPARE (Planning Research and Experimental Procedures on Animals: Recommendations for Excellence) guidelines were published to aid researchers in planning experiments with live animals, providing a checklist for designing studies and also potentially for those in the process of evaluating proposals for animal studies (Smith et al., 2018).

$$
\text { A survey by Bennett et al. (2016), which considered the top } 250 \text { peer-reviewed ISI-rated }
$$
journals for fish research (defined by numbers of fish papers), discovered that while $54 \%$ made some mention of animal ethics in their author guidelines, only $18 \%$ required adherence to a specific guiding document for successful submission. $46 \%$ of journals surveyed made no 
mention of animal ethics requirements in their instructions to authors or publication policies. It is obviously not possible to tell from this survey, whether those journals not mentioning ethics in their policies still scrutinise papers for ethical concerns, however, their survey does highlight an area where perhaps more could be done to raise awareness of fish welfare, by guiding researchers to relevant information and/or training, and questioning unethical treatment of fishes.

\section{The application of the $3 R s$ in fish research}

Much of the legislation around animal experimentation is based on the ' $3 R$ s'. The 3 Rs were originally put forward by Russell \& Burch (1959) to prevent and reduce pain and suffering of animals in research. They are Replacement, Reduction and Refinement. In conforming to the 3Rs, we should, therefore, first ask ourselves the question 'Do we need to use live animals for our research?' or is there an alternative that would allow us to replace animal experimentation. If the answer is yes, that there is no suitable alternative for our scientific objectives, then the second question we must ask is 'How do we minimise the number of animals used without compromising gain in scientific knowledge?' i.e. how can we reduce the number of animals used in experimentation. Finally, we need to ask 'How can we minimise the amount of pain or lasting harm experienced by an animal during experimentation?' as a way to refine our experimental approach. Curzer et al. (2013) advocate the addition of a fourth ' $\mathrm{R}$ ', Refusal, where research plans that are unlikely to provide any scientific gain are rejected before initiation.

Traditionally, the 3Rs have been applied to laboratory animal models where focus is on the individual animals used in an experiment. As fish researchers, much of our work is not limited to laboratory experiments and thus our ethical approach must transcend the laboratory boundaries. Curzer et al. (2013) promote the expansion of the 3Rs/4Rs approach to whole ecosystems, where there is a need to consider not only the particular species of interest, but also the impact of our research on the ecosystem as a whole. They extend the principle of the ' $\mathrm{R}$ 's beyond individual animals to the populations and ecosystems to which they belong. Although, their intention is primarily to translate the $3 \mathrm{Rs}$ into principles for researchers 
whose focus is ecosystem rather than individual based, we believe their paper provides interesting questions for field studies on fishes. Additional questions then become 'Can our research ecosystem be replaced with a different ecosystem that will be harmed less without decreasing the amount of knowledge gained?' (Replacement), 'Are there ways we can reduce harm to the ecosystem by sampling different parts which will harm the ecosystem less but achieve the same scientific outcomes?' for example spatial, temporal or ontogenetic variants (Reduction) and 'Can we change the research procedure in order to decrease the amount of harm to the ecosystem as a whole?' e.g. sampling methods. (Refinement). Of course the fourth R proposed by Curzer et al. (2013) remains the same: if the harm to the ecosystem outweighs any scientific contribution, or no scientific contribution will be gained, the experimental plan should simply be rejected.

\section{Animal alternatives (Replacement)}

For some scientific questions, it may be possible to use animal alternatives to inform fish biology. As 'replacement' has become an increased focus for mammalian studies, there has been an increase in fundamental research in fishes as replacements for mammalian model organisms. However, under the laws of many countries, legislation applies equally to fishes as it does mammals and only young pre-feeding fishes are considered replacement. Nevertheless, full replacement of fishes in experimental research can include living in vitro cultures or computer models which still achieve the scientific objectives and answer the scientific question but without the use of live fishes (reviewed by Schaeck et al., 2013). A large number of cell lines are available for a range of species (Lakra et al., 2011), with the first continuous cell line (RTG-2) dating back to the 1960s (Wolf \& Quimby, 1962). Fish cell lines have been used widely as a replacement for live fishes, to investigate effects of toxicants such as metals and endocrine disruptors (Bols et al., 2005; Navas \& Segner, 2006; Bopp et al., 2008). Cell culture can also be used to address our fundamental understanding of fish physiology (Wood et al., 2002).

\footnotetext{
The term 'replacement' may not always refer to the full replacement of animals, but is used when live animals are not experimented on. Thus, organ preparations, where the fish is killed
} 
and its organs maintained in situ or in culture, can be considered as 'replacement' for the use of live fishes in experimentation. Organ preparations provide a link between cell culture techniques and whole organism effects, providing an additional element of tissue complexity. Examples of organ cultures include intestinal perfusion to investigate the effects of toxicants or to further our understanding of fish osmoregulation (Sundell \& Björnsson, 1988; Hoyle \& Handy, 2005). Methods for in vitro perfusion of the brain have also been used to study the fundamentals of fish endocrinology. Once a sufficient biological understanding is achieved, it may also be possible to replace specific in vitro techniques with computer modelling to remove the need for animal tissue. It seems unlikely that computer modelling will ever fully replace animal experimentation but computer modelling may also allow better targeting of experimental work. Computer models that have been successfully used to determine the toxicity of compounds include Quantity Structure-Activity Relationship (QSAR) models (Moore et al., 2003), the Biotic Ligand Model (BLM) and related models (Paquin et al., 2002; Brix et al., 2017) and Physiologically-based Pharmacokinetic (PBPK) models (Abbas \& Hayton, 1997; Thomann et al., 1997).

\section{Partial replacement is where vertebrate animals are replaced with embryonic life-stages or} invertebrate animals (https://www.nc3rs.org.uk/the-3rs), under the assumption that they are less sentient. This in itself raises moral and ethical questions as to how we determine which animals should be afforded ethical treatment (Bateson, 1991; Brown, 2015) as 'less sentient' could easily be replaced with 'less researched' or 'less understood'. Animal legislation may also vary from country to country in terms of what is an 'animal' when used in scientific experiments. UK law considers 'fishes' in terms of use in scientific procedures to be those which are capable of independent feeding. Similarly, Canadian guidelines do not require ethical clearance for yolk-sac dependent embryos (see Box 1 Sneddon et al., 2017 for details on other countries). The time to independent feeding from fertilisation varies considerably depending on the species. In zebrafish Danio rerio (Hamilton 1822), feeding starts around 45 days post-fertilisation but for other species such as salmonids this period may take several months. The use of fish embryos instead of later stages is therefore considered partial replacement and has been used extensively in toxicity studies with a move to use the fish embryo test (FET) as a replacement for the acute fish toxicity (AFT) test (Belanger et al., 2013; Schaeck et al., 2013; Sneddon et al., 2017). This arbitrary cut-off point in guidance and legislation should be considered from an ethical standpoint with caution. To some it seems 
counter-intuitive to think of the use of embryos instead of adults as animal 'replacement' and recent evidence suggests that larval zebrafish respond in much the same way to noxious stimuli as adults (Lopez-Luna et al., 2017a). Whether or not we believe that embryos should be afforded the same ethical considerations as adults, the ways in which we treat embryos, including euthanasia and husbandry, merit consideration.

\section{Sample Size (Reduction)}

It is imperative when experiments are designed to use live fishes, that we minimise the number of animals used, but maintain the scientific rigour with which we test hypotheses. On the one hand, sampling more individuals than is necessary to robustly statistically test a hypothesis may subject more animals than necessary to potential pain and suffering and would be deemed unethical. On the other hand, not sampling enough individuals, could lead to a data set that cannot adequately address a hypothesis, rendering the data set unusable. From an ethical perspective, this results in a number of animals being used with no scientific gain, which perhaps fits more with the Reject definition of ' $R$ ' described above.

Various resources can be used to estimate required sample sizes prior to the start of an experiment. Power analysis is a common method for determining the smallest sample size that can be used to detect an effect at a specific level of significance (Festing \& Altman, 2002) and for simple experimental designs can make use of freely available software. Power calculations for more complex experimental designs are likely to require input from a statistician. Power analyses generally rely on availability of previous data or pilot data; thus the provision of raw data by researchers can increase the usefulness of experiments as it can be used for future power analyses, meta analyses or further statistical analysis (Festing \& Altman, 2002). However, power analyses are closely related to the $\mathrm{P}$ value, and it has been argued that interpretation of data based on $\mathrm{P}$ values can lead to incorrect conclusions. Therefore, consideration of the effect size is also important (Sneddon et al., 2017). Additionally, it is not uncommon to see comments within manuscripts where samples have been lost due to equipment malfunction; thus a perfectly designed experiment based entirely on power analysis, may fall short if a few samples are lost through technical or human error. 
Experiments with early life stages may also be subject to high natural mortality (Wilson et $a l ., 2018)$. Thus while every effort should always be used to minimise the number of fishes used in live experiments, there may also be circumstances where it is necessary to use more animals than predicted by power analyses. Where research is feeding into management of fisheries, it may be necessary to have large sample sizes to meet legal regulatory requirements and/or to be of use to management strategies (Cooke et al., 2016a). Nonsignificant results may often be disregarded through academic pressures, yet the publication of these data may be of benefit to the design of future animal experiments by other researchers (Fanelli, 2010; Dwan et al., 2013).

\section{Improving experiments on live fishes from a welfare perspective (Refinement)}

There are many instances when it is not possible to replace live fishes in experiments, therefore, the remainder of this review focuses on refinement. Compromised welfare will be reflected in behavioural and physiological alterations, thus a fish whose welfare is compromised is likely to yield unreliable data. Therefore, it is imperative for both fishes and researchers that we consider how to refine fish welfare within our experiments.

As fishes are the most speciose of all the vertebrates, the range of fish species that could potentially be used for experimental research is vast. That said, the majority of lab-based fish work focuses around a handful of species. In terms of scientific rigour, the fish species chosen must be appropriate to the study objectives. Therefore, choice of species requires knowledge of their life-history, behaviour, physiology and genetics along with husbandry requirements for laboratory studies (ASAB, 2012, 2018). Within certain model species, there are also genetic strains which may differ phenotypically (e.g. Séguret et al., 2016; van den Bos et al., 2017) and the most appropriate strain for the experimental question must be considered.

Some studies, particularly field studies, may involve work with endangered or protected fish species. Lethal studies involving endangered species are controversial (Heupel \& 
Simpfendorfer, 2010; Minteer et al., 2014) and are likely only to be justified if the conservation benefit to the species as a whole significantly out-weighs the cost to the individuals and the population affected by sampling. Ethical decisions regarding lethal sampling or removal from the wild are often influenced by public, media and political pressures making decisions based on scientific evidence important (Heupel \& Simpfendorfer, 2010). Lethal sampling or collection for laboratory studies are not the only factors which require ethical consideration; simple observation also has the potential to disrupt habitats and behaviours of threatened species, so attention must be paid to both the individual and environmental cost.

When removing fishes from the wild or purchasing fishes for laboratory studies, regulations exist for species threatened with extinction (Appendix I cites) and those that are not necessarily now threatened with extinction, but may become so unless trade is regulated (Appendix II cites; https://www.cites.org/). Movement of fishes also has the potential to introduce 'invasive' species to naïve ecosystems, indeed many exotic species have been historically introduced on a global scale. Unintentional release of both non-native and native fishes can lead to the spread of disease in wild populations and in fishes, unlike in most vertebrates, domestic sources of infection in wild populations, rather than wild sources have been identified as the most important driver of emerging infectious diseases (Tompkins et al., 2015). While a large proportion of unintentional releases can be attributed to aquaculture and the ornamental fish trade, researchers must take care that they are not contributing to this problem. It should also be remembered that 'invasive' fishes are no 'less' of a fish thus even when it is necessary to carry out targeted removal from a non-native habitat this should be done as humanely as possible.

\section{Do Fishes Experience Pain?}

In choosing refinements to apply, as fish researchers we are likely to at least have an opinion on whether fishes experience pain. The ability to react to potentially damaging stimuli is seen in all animals and is mediated through nociception, which is innervated by sensory receptors that convey information on injury to the central nervous system (Sneddon, 2018). In humans 
it is accepted that nociception leads to the sensation or feeling of pain, which is often defined as an unpleasant sensory and emotional experience associated with actual or potential tissue damage (IASP, 1979). Noxious stimuli are extremes of temperature, high mechanical pressure and chemicals (e.g. acids, venoms) that excite nociceptors, receptors that preferentially detect injurious stimuli. In pain assessment, humans self-report their feelings of the intensity, type and duration of pain but animals do not share our language. Therefore, assessing pain in non-human animals is based upon detecting changes in behaviour and physiology when applying a damaging stimulus that would cause pain to humans (Sneddon et al., 2014).

Nociceptors have been identified in non-human mammals and other vertebrate groups such as amphibian, reptilian and avian species but can also be found in invertebrates (reviews in Sneddon et al., 2014; Sneddon, 2015, 2018). Empirical studies in fishes have also confirmed the presence of nociceptors, demonstrating their properties are very similar to those found in humans and other mammals (Sneddon, 2002, 2003a, 2018; Ashley et al., 2006, 2007; Mettam et al., 2012). Studies in fishes have demonstrated changes in brain activity during noxious stimuli (Dunlop \& Laming, 2005; Nordgreen et al., 2007; Reilly et al., 2008a; Sneddon, 2011) and recorded adverse changes in behaviour and physiology during noxious treatments (Sneddon et al., 2003a,b; Sneddon, 2003b; Dunlop et al., 2006; Reilly et al., 2008b; Roques et al., 2010; Mettam et al., 2011; Maximino, 2011; White et al., 2017) all of which can be prevented by analgesics known to be effective in relieving pain in mammals (Sneddon, 2003b, 2012; Newby et al., 2009; Nordgreen et al., 2009; Mettam et al., 2011; Schroeder \& Sneddon, 2017; Lopez-Luna et al., 2017a,b,c,d; Taylor et al., 2017). This empirical evidence taken together supports the idea that fishes may experience pain.

\section{Whole Animal Responses to Noxious Stimuli}

The rainbow trout Oncorhynchus mykiss (Walbaum 1792), was the first teleost model shown to possess nociceptors in 2002 (Sneddon, 2002, 2003a): these nociceptors are A-delta and C fibres that act as nociceptors in humans and other mammals. Nociceptors have also been identified in agnathans (Matthews \& Wicklegren, 1978) but studies have not yet found 
nociceptors in elasmobranchs where a lack of C fibres has been reported (e.g. Snow et al., 1996). The rainbow trout has three types of nociceptors including polymodal (mechanical, thermal and chemical stimuli), mechanothermal (no response to chemicals) and mechanochemical (no response to temperature) (Sneddon, 2003a; Ashley et al., 2006; 2007; Mettam et al., 2012). A relatively lower percentage of trout nociceptors are C fibres (4-5\%, Sneddon, 2002; Roques et al., 2010) compared with terrestrial vertebrates (50\%; Young, 1977) although reptiles also have a low percentage of C fibres (Terashima \& Liang, 1994). Some researchers suggest that the small number of $\mathrm{C}$ fibres means teleosts cannot experience pain (Rose et al., 2014), however, it could be argued that A-delta fibres conduct more rapidly, so the fish system may react faster. The trout A-delta fibres perform the same function as mammalian $\mathrm{C}$ fibres reacting to different types of noxious stimuli and many are polymodal nociceptors (Sneddon, 2002, 2003a; Ashley et al., 2006, 2007; Roques et al., 2010; Mettam et al., 2012).

Fish sensory neuroanatomical pathways are fairly conserved from an evolutionary perspective when compared with mammals (Sneddon, 2004). Within the teleost brain there are various connections to important processing areas including the thalamus and cortical areas (Rink \& Wulliman, 2004) that in mammals are used for pain responses. Higher brain areas rather than just the spinal cord and hindbrain reflex centres respond during noxious events in teleost fishes (Dunlop \& Laming, 2005; Nordgreen et al., 2007; Reilly et al., 2008a; Sneddon, 2011) thus the response to noxious stimuli is not restricted to the reflex centres as once suggested (Rose, 2002). Fishes learn to avoid potentially painful stimuli usually in one or a few trials (e.g. Yoshida \& Hirano, 2010) and avoidance behaviour can continue for several days (Dunlop et al., 2006; Millsopp \& Laming, 2008). Protracted, complicated responses are exhibited by a variety of fish species during a noxious event (reviewed in Sneddon, 2009, 2015). Normal behaviours such as feeding and swimming can be suspended during noxious events (Sneddon, 2003b; Reilly et al., 2008b; Correia et al., 2011a; Roques et al., 2012). Guarding behaviour is also seen in response to noxious stimuli, where a fish will avoid using an area where a noxious stimulus has been applied. For example, rainbow trout suspend eating after an acid injection to the lips for up $3 \mathrm{~h}$, unlike control individuals and those treated with analgesic (Sneddon, 2003b). Other physiological responses to noxious stimuli include elevated opercular beat rate and elevated stress hormone (cortisol) concentrations (Sneddon, 2003b; Ashley et al., 2009; Roques et al., 2012). 
If an experience alters future behaviour and decision making as well as motivational state then it must be important to the animal. Thus if a potentially painful treatment results in longterm behavioural alterations then this provides insight into the significance and importance of pain. In mammals, self-administration paradigms involve gauging the propensity to selfmedicate with analgesics. Here, food or water is medicated and animals can self-select this analgesia-laden water or food to reduce their pain, suggesting an internal mental experience or affective component to pain (e.g. Pham et al., 2010). Unfortunately this approach does not work with fishes as they suspend feeding for the duration of noxious stimuli (Sneddon, 2009). An alternative is to determine whether the fish will endure a cost to accessing analgesia. If pain is a negative internal state then fishes should pay a cost in either added physical effort or relinquish access to a resource or preferred area to obtain access to analgesia. For example, zebrafish, subjected to a noxious stimuli lost their preference for favourable enrichment and instead chose unfavourable barren areas with dissolved analgesic (Sneddon, 2011) suggesting that zebrafish will seek substances known to induce pain-relief in mammals, and are willing to endure a cost to access analgesia in an unfavourable environment.

The Debate Surrounding Pain in Fish

Those that do not believe fishes experience pain have argued that animals must have a human cortical structure to consciously experience pain. Because fishes lack a multi-layered, humanlike cortex, it is argued that they are not aware of pain and do not feel discomfort or suffer (Rose, 2002). However, as described above there is growing empirical evidence that supports the concept of pain in fishes, and that this is a significant and negative state (Broom, 2007, 2014; Brown, 2015; Chandroo et al., 2004; Sneddon, 2009, 2011, 2015; Sneddon et al., 2014). The hypothesis that a function such as pain suddenly arises in humans without any precursor challenges evolutionary laws (Sneddon, 2009). Recent commentaries argue for 414 (Merker, 2016) and against (Key, 2016) a fish's ability to perceive pain and have stimulated much debate (Animal Sentience, 2016). These debates can become semantic arguments and 
systematic review of the evidence by independent parties has been suggested as a way forward (Cooke, 2016). Regardless, we cannot communicate directly with fishes thus selfreporting of pain is impossible. If we believe that empirical evidence suggests that fish responses fulfil the definition of animal pain, then from an ethical and moral perspective we should err on the side of caution to protect their health and welfare.

\section{Common Considerations for Laboratory and Field Studies}

\section{Anaesthesia}

The use of anaesthetics in fishes has been researched extensively, particularly with regard to the physiological effects they cause (reviewed by Ross \& Ross, 2008; Matthews \& Varga, 2012). However, the first decision a researcher has to address is when is it appropriate to use anaesthetic? Anaesthesia is generally recommended for any invasive procedure where the fish needs to be immobilised, but there are variations on what this means. Some researchers recommend anaesthesia for routine husbandry procedures such as weighing fishes, as struggling by the fish has the potential to cause injury both to the fish and the researcher. Inaccuracy of measurements due to movement of the fish may also occur. However, many researchers would argue that anaesthesia itself is stressful, with subsequent physiological effects, and so where handling is minimal and procedures are non-invasive or minimally invasive, the then use of anaesthesia may be counterintuitive (Cooke et al., 2016a). For field studies there is the added complication that fishes will be released with some anaesthetic agents requiring a withdrawal period before fishes can be released into the wild (Wargo Rub et al., 2014; Bennett et al., 2016), for example if the fish may be caught for subsequent human consumption (Ross \& Ross, 2008). Anaesthesia may also alter physiology and behaviour such that the likelihood of post-release predation increases (Cooke et al. 2016a). Therefore, deciding whether anaesthetics should be used must be assessed on a case-by-case basis, with regard to the welfare of the fish and the circumstances under which it will be used. 
For some larger fish species where it is impractical to use anaesthesia e.g. sharks, it may be possible to use alternatives to anaesthesia such as tonic immobility (Kessel et al., 2015). Holland et al. (1999) used tonic immobility for external and internal (surgical implantation) attachment of acoustic transmitters and found that within a few seconds to a few minutes, tiger sharks Galeocerdo cuvier (Péron \& Lesueur 1822) showed tonic immobility after inversion. However, while tonic immobility [and other similar techniques such as atonic immobility (Wells et al., 2005)] may reduce fish movement and therefore risk of injury to the fish and researcher, more research is needed to understand the stress associated with tonic immobility itself. In lemon sharks Negaprion brevirostris (Poey 1868), tonic immobility was found to be a stressful experience which magnified changes in blood chemistry parameters (Brooks et al., 2011a).

If anaesthesia is to be used, the decision of which anaesthetic to use is often influenced by availability, cost effectiveness, ease of use, nature of study and safety for user (Cho \& Heath, 2000). For fishes, the usual route of anaesthesia is via immersion, although injection is also used. Periods of immersion necessary to induce anaesthesia will depend on the ventilatory mechanism of the fish, for example air breathing fishes may require a much longer immersion period than fishes which rely entirely on dissolved oxygen from the water (Ross \& Ross 2008; Neiffer \& Stamper, 2009). There are a variety of different anaesthetics available which can be added to the water and work through different physiological mechanisms. Commonly used compounds include MS222 (tricaine methanesulfonate; ethyl 3aminobenzoate methanesulfonate), benzocaine (ethyl-4-aminobenzoate), etomidate, eugenol (4-allyl-2-methoxyphenol; the active ingredient of clove oil), AQUI-STM (active ingredient isoeugenol), metomidate and 2-phenoxyethanol (Neiffer \& Stamper, 2009). Carbon dioxide has been used as an anaesthetic for fishes, and results in cerebral hypoxia. However, its use is controversial for several reasons, including observed struggling of fishes as anaesthesia is induced and then removed (Wargo Rub et al., 2014) and the difficulty in achieving controlled anaesthesia compared to other drugs (Ross \& Ross, 2008). The use of non-chemical methods of anaesthesia such as cooling and electro-immobilisation are also controversial as anaesthestics. While cooling may immobilise the fish, it does not completely block nerve conduction (Matthews \& Varga, 2012) and it is unlikely that true anaesthesia and analgesia are achieved (Ross \& Ross, 2008). Hence, cooling is generally not an accepted method of anaesthesia in Europe (Lidster et al., 2017). Electro-immobilisation is not recommended due 
to its narrow safety margin between anaesthesia and injury (Wargo Rub et al., 2014) and the level of anaesthesia and analgesia achieved remains uncertain (Ross \& Ross, 2008). The choice of which chemical anaesthetic to be used will be influenced by a range of factors, not least which can be legally purchased by the researcher. From an ethical perspective, it is important that the researcher understands how the chosen anaesthetic works and any potential lasting physiological changes that may be induced. For example, addition of MS222 to fresh water usually results in a lowered $\mathrm{pH}$, and therefore requires buffering, or it can cause plasma acidosis in the fish. Anaesthetic agents can also alter the physiology of fishes in different ways, thus potentially confounding comparisons between physiological studies that have used different chemical routes of anaesthesia (Small, 2003; Holloway et al., 2004).

Often absent from the list of things to consider when choosing an anaesthetic chemical is the welfare of the fish itself in response to the anaesthetic agent. Recent work has highlighted that the way fishes respond behaviourally to anaesthetic exposure is species-specific. Readman et al. (2017) argue that in addition to assessing the ease of delivery, and rate and stability of anaesthesia, researchers should also consider the way a fish responds to anaesthesia when initially exposed to the chemical. Zebrafish demonstrate a negative behavioural response when exposed to benzocaine and MS222 (Readman et al., 2013) and appear to remember exposure to some anaesthetics (Wong et al., 2014). Medaka Oryzias latipes (Temminck \& Schlegel 1846) also show a negative behavioural response to these chemicals, whereas carp Cyprinus carpio L. 1758 and rainbow trout do not (Readman et al., 2017). Clearly further research is warranted on the welfare of anaesthesia practice in fishes, along with discussions at regulatory levels to ensure that chemicals with the greatest welfare potential are accessible. Reporting of anaesthesia details, including concentrations, buffering, duration and mention of behavioural responses would allow for better comparison between studies and may contribute to enhancing fish welfare in this area.

\section{Analgesia}

\section{If we accept that a potentially painful event substantially alters behaviour and physiology in} fishes we should attempt to minimise or alleviate this. Drugs with analgesic properties could 
be employed during any invasive procedures such as invasive tagging, surgery, cannulation, exposure to noxious chemicals or after damage to the fish occurs via factors such as net abrasion or injuries from aggressive encounters or diseases. The major classes of analgesic drugs are opioids, nonsteroidal anti-inflammatory drugs (NSAIDs), local anaesthetics, and miscellaneous drugs that have pain-relieving properties (e.g. anti-depressants). Opioids, NSAIDs and local anaesthetics have been investigated with regards to analgesia in fishes (Table 1; Sneddon, 2012).

Opioids act on the three opioid receptors (mu, delta and kappa) located on neuronal cell membranes to produce analgesia. A classic example of such a drug is morphine. Opioids inhibit neurotransmitter release presynaptically thereby blocking nociceptors but these drugs also block central transmission. Several studies have shown morphine is an effective analgesic in rainbow trout (Sneddon, 2003b; Baker et al., 2013; Jones et al., 2012) and other species (e.g. goldfish Carassius auratus (L. 1758), Nordgreen et al., 2009; zebrafish, LopezLuna et al., 2017a,b,c,d; Magalhaes et al., 2017; Schroeder \& Sneddon, 2017; Taylor et al., 2017). Morphine has a pharmocokinetically similar action in fishes compared with mammals, however, morphine persists for a prolonged period after administration due to slower excretion rates (half-life 37 h; Newby et al., 2006, 2009). Thus it may be preferable to use morphine in long term situations and peri- or post-operatively since one dose may be all that is required. Other opioids have been studied. For example, tramadol, dermorphine and $\beta$ casomorphin reduced the magnitude of response to electric shock in cod Gadus morhua L. 1758, carp and rainbow trout (Chervova \& Lapshin, 2000; Chervova et al., 1994). Butorphanol has been explored in the chain dogfish Scyliorhinus rotifer (Garman 1881) and carp as part of a combined anaesthetic protocol but appeared to have limited effectiveness (Davis et al., 2006; Harms et al., 2005). Buprenorphine also has poor analgesic properties in rainbow trout (Mettam et al., 2011; Baker et al., 2013), with studies showing a depressive effect on the cardioventilatory system (Gräns et al., 2014). However, Curtwright et al. (2015) used buprenorphine to effectively reduce responses to noxious heat in larval zebrafish when they were immersed in $0.3 \mathrm{mg} \mathrm{ml}^{-1}$.

NSAIDs inhibit arachidonate cyclo-oxygenase (COX) enzymes to reduce the production of thromboxanes and prostaglandins providing anti-inflammatory, anti-pyretic and analgesic 
properties (Rang et al., 2003). Ketoprofen was found to be ineffective in the chain dogfish to determine the minimum anaesthetic concentration of MS-222 required to prevent a response to an acute noxious stimulus (Davis et al., 2006). Ketoprofen did reduce some indicators of muscle damage after surgery in carp but did not prevent behavioural changes (Harms et al., 2005). Carprofen had some efficacy in rainbow trout during noxious stimulation, with trout resuming normal feeding more quickly than trout with no carprofen. However, this drug depressed activity even in control trout which may be an undesirable side effect (Mettam et al., 2011). Rizzo et al. (2017) tested the impact of flunixin, ketorolac and ketoprofen in rainbow trout, none of which appeared to be effective at ameliorating an increase in opercular beat rate $2 \mathrm{~h}$ after surgery at the doses employed in the study. Indomethacin injected intraperitoneally $\left(20 \mu \mathrm{l}\right.$ of $\left.0.2 \mathrm{mg} \mathrm{ml}^{-1}\right)$ did reduce pain related responses in adult zebrafish treated with formalin (Magalhaes et al., 2017). Aspirin administered via immersion prevented the reduced activity seen in adult and larval zebrafish when subjected to noxious events (Lopez-Luna et al., 2017a,b,c,d; Schroeder \& Sneddon, 2017). Future studies need to investigate NSAIDs further to determine the minimum effective dose and explore any unwanted side-effects since long term use of these drugs in mammals, birds and reptiles can result in gastric ulcers or renal disease.

Local anaesthetics act by inhibiting the propagation of action potentials via blockade of sodium channels and by affecting membrane function (Rang et al., 2003). Therefore, they prevent pain sensation by blocking transmission of nociceptive signals. Relatively few studies have explored local anaesthetics, however, novocaine is known to reduce reflex responses to electric shock in cod (Chervova, 1997) but more information is required before it can be recommended. Lidocaine effectively prevents behavioural and physiological alterations in rainbow trout during subcutaneous injection of acetic acid (Mettam et al., 2011). Exposure to lidocaine by emersion also ameliorates substantial changes in the behaviour of adult zebrafish subject to caudal fin clipping (Schroeder \& Sneddon, 2017) and was also effective when used with larval zebrafish exposed to noxious chemical and thermal stimuli (Lopez-Luna et al., $2017 \mathrm{a}, \mathrm{b}, \mathrm{c}, \mathrm{d})$. More research is necessary to test the wide range of local anaesthetics on a range of fish species to construct reliable analgesic protocols. As the use of analgesics increases in fish research, it is important that more fundamental studies investigate both the potential benefits of analgesic use for fish welfare, but also any adverse effects. 


\section{Tagging}

575

Visual identification

577

578 Phenotypic methods represent the least invasive methods of identifying individuals and have

579 been used in many studies. These can be simple uses of visual assessment such as scale patterns in carp (Huntingford et al., 2013) or the use of software to generate identification of white-spotted eagle rays, Aetobatus narinari (Euphrasen 1790) (Flowers et al., 2017).

582 However, for a large number of species individual identification is not possible by eye, and methods of marking individuals are needed. Colour marks are commonly used, either as small pieces of coloured material attached to the fish or temporary colour marks applied onto or just beneath the skin. Attachment of small coloured labels (e.g. coloured beads, discs) to fishes has been used successfully in a number of species (Sloman et al., 2005; Webster \& Laland, 2009). Traditional methods of marking the skin include dyes such as alcian blue (Kelly, 1967), and freeze-branding with liquid nitrogen (Nahhas \& Jones, 1980; Bangs et al., 2013) but more recently, fluorescent dyes such as VIE tags (Visible Implant Elastomer; http://www.nmt.us/products/vie/vie.shtml) have been developed. VIE tags are likely to cause minimal harm to the fish and have been used and evaluated extensively (Malone et al., 1999;

592 Reeves \& Buckmeier, 2011; Hohn \& Petrie-Hanson, 2013; White \& Brown, 2013). However, there has been a relatively limited number of studies focussed on understanding the behavioural implications of colour tagging where the addition of colour has the potential to alter natural behaviours (Frommen et al., 2015). Fishes can also be tagged with marks not visible to the naked human eye. For example, immersion in the fluorochrome dye, calcein, produces a distinct calcein mark on the fin rays and scales which are visible under a

598 fluorescent microscope (Leips et al., 2001; Mohler, 2003). This is particularly useful for 599 batch-marking or tracking cohorts of fishes. Another way of marking individuals is fin 600 clipping, where a portion of the fin, usually the caudal fin, is removed. Adipose fin removal 601 in salmonids has been widely used for many years to distinguish hatchery-reared fishes from wild salmonids. However, some ethical considerations of fin clipping both for identification and genetic analyses are given in Table 2. 
Beyond visually tagging individuals, devices can be attached to, or implanted within individuals to keep track of their identity and movements. There are a variety of different factors which will determine the type of tag used and individual validation studies are important for determining whether the intended tag is suitable for the target animal. Validation studies are typically designed to observe the effects of tags on swimming kinematics, swimming performance, energy expenditure (measured as oxygen uptake rates) while swimming or at rest, behaviour, or survivorship (Ross \& McCormick, 1981; Lowe, 1996; Lefrançois et al., 2001; Makiguchi \& Ueda, 2009; Bouyoucos et al., 2017). It is unclear, however, what constitutes an acceptable level of impairment to the aforementioned metrics due to tagging. Indeed, tag burden will differ based on the size/life stage of the fish. Ultimately, validation should be conducted to determine, firstly, whether the intended tag can be deployed on the target individuals and whether the tag or target species/life stage can be refined. If the tag is deployed, any consequences of tag bearing should be documented.

The so-called " $2 \%$ rule" that is often referenced suggests that tags (both external and internal) within $2 \%$ of the target individual's mass should not produce negative consequences (Jepsen et al., 2015). This should not be considered definitive as some studies that have adhered to the $2 \%$ rule have observed tagging effects (e.g. Brown et al., 1999) and some fishes are able to endure tag burdens greater than $2 \%$. For example, tags of $5-10 \%$ body mass were successfully used to track the migration of 2-year-old sockeye salmon smolts Oncorhynchus nerka (Walbaum 1792) from freshwater natal grounds to the open ocean (Clark et al., 2016). Indeed, adding a tag will increase the mass of an animal, but it is arguably more relevant to an aquatic organism to consider changes in buoyancy (i.e. submerged weight), rather than changes in absolute mass for establishing acceptable characteristics of external tags to be applied across species. For instance, two tag packages with similar masses (e.g. floating versus neutral or negatively buoyant tags) would have very different consequences for buoyancy compensation. Furthermore, for external tags, the $2 \%$ rule neglects acceptable limits for induced hydrodynamic drag, which will have profound effects on energy expenditure, as drag scales exponentially with swimming speed. 
637 Popular telemetry devices, such as pop-up satellite archival tags (PSAT) or acoustic 638 transmitters, can be applied both externally and internally. Telemetry devices, rather than 639 logging devices that must be physically retrieved to collect data, afford researchers the 640 opportunity to remotely observe an animal in its habitat with minimal disturbance (Cooke et al., 2004, 2016b; Block et al., 2011; Hussey et al., 2015). Telemetry studies using external tags must consider removal or retrieval of inert tags or tag attachment gear (e.g. bridles) to avoid lifetime consequences for tag-bearing animals. A popular approach for external tags is the use of corrodible galvanized components of the tag package, the corrosion of which is triggered by the device itself under predefined conditions, or as a function of the ambient water's physical conditions (e.g. Speed et al., 2013; Whitmore et al., 2016). However, this method comes with the risk of tag packages not detaching (with long-term consequences for the animal), or detaching prematurely (with consequences for data collection). Tags can be permanently affixed to eliminate the chance of premature detachment, but strategies to recapture animals and remove tags ought to be considered.

External Tags

More substantial external tags have the potential to affect buoyancy and increase effort to overcome hydrodynamic drag while swimming (Jepsen et al., 2015). When alterations in buoyancy and drag become excessive, external tags can confer negative sub-lethal or lethal consequences to the tag-bearing individual. For example, external tags can affect the swimming kinematics, activity levels, and swimming performance of the target species (Methling et al., 2011; Bouyoucos et al., 2017). Biofouling in the field and laboratory can further alter the physical properties of external tags (Thorstad et al., 2001). Swimming with increased hydrodynamic drag, and compensating for changes in buoyancy can increase a tagged fish's energy expenditure (Lowe et al., 1998; Lefrançois et al., 2001; Steinhausen et al., 2006; Methling et al., 2011) leading to reduced growth rates, delayed maturation (McFarlane \& Beamish, 1990; Manire \& Gruber, 1991; Sykes et al., 2012) reduced foraging ability and ability to escape predators (Ross \& McCormick, 1981; Feltham \& MacLean, 1996; Adams et al., 1998). As such, the inappropriate application of external tags to fishes can have direct consequences for individuals. 
669 If externally-attached tags are used over long periods of time, new tissue may grow around 670 the tag, thereby enveloping the device (Lucas, 1989; Bauer \& Loupal, 2007). Alternatively, 671 fishes can expel tags from the tissue site of attachment and abrasions, loss of scales, or 672 wounds associated with tagging may have pathological outcomes (Makiguchi \& Ueda, 2009).

673 External tags also come with the risk of entanglement, either trapping the animal, or getting 674 torn from the tissue, possibly resulting in a wound. However, in many cases the animal may 675 be able to persist indefinitely with relatively minor impairments associated with bearing an 676 external tag (especially as they grow).

677

Internal Tags

679

An alternative to external attachment is to implant tags into the fish, either within fish tissues or more usually within the peritoneal cavity. Internal tags can vary in size quite considerably and while implantation avoids the potential issues with hydrodynamic drag, large internal tags can still affect buoyancy control. Small implantable tags, such as passive integrated transponder (PIT) tags for identification, can be quickly inserted through a needle into muscle or the peritoneal cavity but surgery may be necessary to implant larger tags, which usually requires anaesthesia (but see alternatives, e.g. tonic immobility in elasmobranchs; Kessel et $a l ., 2015)$ and a recovery period (Cooke et al., 2005). If there is a need to retrieve tags, animals must undergo a second surgical procedure and recovery, unless the second sampling is terminal. Indeed, some implantable tags, such as acoustic transmitters, can last for years with little to no impact on the animal (Smukall et al., 2018); under these circumstances, a second capture event and surgical procedure to remove the tag would be far more invasive than simply leaving the implanted tag. Tags can be inserted gastrically, but are likely to be passed by the fish, unless the target species is no longer eating, as is the case for semelparous salmon during their terminal spawning migrations (Ramstad \& Woody, 2003; Brunnschweiler, 2009; Neely et al., 2009). given fish is in suitable condition for deployment. Collecting fishes in the field for tag 
deployment can be an inherently stressful experience and even fishes in relatively good condition post-release may still become another's meal if it experiences a number of impairments to performance (Raby et al., 2014; Tolentino et al., 2017). Fortuitously, tremendous research effort has gone into defining best-practice approaches to improve the condition of fishes post-release, especially Pacific salmon (Oncorhynchus spp.) (Farrell et al., 2001; Cooke et al., 2012; Cook et al., 2019). Successful use of tagging therefore relies on proper validation of the tag or tag package and consideration of impacts of capture and handling on the fish (Jepsen et al., 2015; Cook et al., 2019).

\section{Fate at the End of the Experiment}

Release

Where possible, many researchers seek to release wild-caught fishes back to their native habitat when they are no longer required for scientific research. Fishes should obviously be in good health when they are released and should be displaying 'normal' behaviour and physiology (Bennett et al., 2016). Animals released in poor physiological condition or exhibiting unusual behaviours are likely to be more vulnerable to predation. While return to its natural environment may be beneficial to the individual fish, the risk to the ecosystem of returning these individuals must be carefully assessed. Primary considerations include whether the fish could have contracted disease or parasites while in captivity and whether they have been exposed to chemical compounds which may be retained in their tissues (e.g. anaesthetics, toxicants) (Wargo Rub et al., 2014; Costello et al., 2016). Some experiments may seek to release fishes reared in captivity to the wild; such releases are likely to be subject to local legislation to ensure no negative effects on native populations. The behaviour of fish held in captivity for long periods may vary markedly from the behaviour of wild fishes, thus care should be taken to enhance the viability of these fishes prior to release (reviewed by Brown \& Laland, 2001). 
731 Where ornamental fishes are used, particularly if they were originally purchased from the ornamental fish trade, it may be possible to rehome fishes following experimental work if they are in full health and without any effects from the experimental work they have been used for. If this is to happen, care should be taken to ensure that their new home is suitable, for example, in line with OATA guidance for fishes purchased within the retail trade (OATA, 2015). The researcher should be confident that the new owner possesses an aquarium or pond that is well established and suitable for the species and it is good practice to provide the new owner with care instructions for their new fishes. Where appropriate, if the social environment is likely to be very different in their new home it may be possible to acclimate the fish, for example to a lower stocking density, before they leave the research facility. Consideration should also be given to the welfare of the fish during transport to their new home (see Transport section below).

\section{Euthanasia}

Euthanasia, the induction of humane death of an animal, may be the only suitable or permissible option at the end of an experiment. There are two main approaches to euthanasia in fishes, physical or chemical. Physical methods include stunning (i.e. a sharp blow to the head) and chemical methods include overdose with anaesthesia (Ross \& Ross, 2008). Whether physical or chemical methods are used, confirmation of death by decapitation or pithing (i.e. destruction of the brain and anterior spinal cord) are recommended (Ross \& Ross, 2008). UK and EU legislation (ASPA, 2013; EU, 2010) favours overdose of anaesthetic or percussion stunning followed by destruction of the brain (Metcalfe \& Craig, 2011). For percussion stunning, prior use of an anaesthetic is advised as long as any distress caused by administration of the anaesthetic is less than that likely to be caused by killing without anaesthetic. Extensive guidelines on euthanasia are also provided by the American Veterinary Medical Association (AVMA, 2007). For larvae where percussion stunning is not appropriate, this is replaced with overdose of anaesthetic followed by killing by emersion in iced water or a fixative (Metcalfe \& Craig, 2011). In many instances, the impact of the 
method chosen (e.g. anaesthesia) may not be resolved within the scientific literature (Hawkins et al., 2016). Therefore it is important that researchers continue to consult the literature regarding the ethics of euthanasia so that best practice is followed.

\section{Holding fishes in the Laboratory}

\section{Transport to the lab}

If fishes are to be used in laboratory experiments then, unless they are bred in-house, they first have to be transported to the lab. Given the range of experimental fish species, the source of fishes will be diverse but there is an ethical responsibility that lies with the researcher to understand where the fish they purchased originated from, for example, ensuring that suppliers of ornamental fishes are not supporting destructive practices of collection (e.g. dynamiting, use of cyanide). Purchasing fishes from a reputable supplier with concern for fish welfare is important and in the UK, the Home Office state that zebrafish used for scientific research should have been bred for that purpose (ASPA, 2013). The main challenges fishes face during transport include stress and injury during handling and preparation for transport, deterioration of water quality during transport leading to increased disease susceptibility, stress and metabolic shock following transport (Pickering et al., 1982; Portz et al., 2006; Sampaio \& Freire, 2016). Handling and transport stressors have the potential to influence later experimental results so a thorough understanding of the history of experimental fishes is important. If fishes are in good health prior to transport they are more likely to cope with the stress of transport and to be free from disease. In addition to fishes obtained from a supplier (commercial or non-commercial), fishes may be wild caught and then transferred to the lab. Here, the stress of capture also needs to be considered as it is likely to affect their ability to cope with transport stress and the ethics of capture techniques for wild fishes are discussed below (see Catch and Release below).
The welfare of fishes transported live for food aquaculture and also in the ornamental fish industry has been studied extensively (e.g. Walster, 2008; European Commission, 2017). 
Fishes supplied for experimental purposes are often transported much shorter distances, but may have previously experienced longer transport times. Maintenance of good water quality during transport is essential. For very short durations, ensuring sufficient oxygen levels and appropriate temperature are the primary concerns as these are the parameters that will change the quickest. Although many fish species can tolerate a period of hypoxia, hypoxia will induce physiological changes (Montpetit \& Perry, 1998). Fishes are often transported in bags and for short periods of transport, adding oxygen or air to the bag is common practice (Amend et al., 1982; Froese, 1988). Other alternatives for avoiding problems with oxygen demand include reducing metabolic rate of the fish via sedation or reduced water temperatures. Both of these methods will cause physiological changes. During transport, accumulation of carbon dioxide leads to a decrease in water pH (Sampaio \& Freire, 2016). If the duration of transport is long enough for this to occur, buffers can be added to the water to maintain pH such as Tris buffer (Amend et al., 1982; Singh et al., 2004), pH buffer 8.3 Trizma® (Stuart et al., 2013), sodium bicarbonate and sodium carbonate (Correia et al., 2011b).

Ammonia is the main nitrogenous waste product of fishes and is excreted primarily via the gills. Total ammonia nitrogen (TAN) comprises un-ionised $\left(\mathrm{NH}_{3}\right)$ and ionised ammonia $\left(\mathrm{NH}_{4}{ }^{+}\right)$with high levels of the former causing convulsion, coma and death in fishes (Wright \& Wood, 2012). Confinement in a small space, whether this be in tanks or in transport bags, allows water ammonia concentrations to rise, with TAN composition depending on temperature and $\mathrm{pH}$ (Portz et al., 2006). For a transport period of short duration with good water quality at the start of transport, ammonia toxicity is unlikely to be an issue. For longer transport periods there are two main strategies for mitigating the effects of elevated TAN. Withdrawal of food prior to transport reduces ammonia excretion and has the additional benefits of reducing metabolic rate (Lim et al., 2003; Walster, 2008) and preventing regurgitation of food during transport. Alternatively chemicals such as zeolites or AmQuel@ can be added to the water to bind ammonia.

In addition to maintaining good water quality, there are a plethora of chemicals and commercial products that have been investigated for their potential to alleviate stress during transport (Vanderzwalmen et al., 2018). While further research is needed for many of these 
compounds in terms of their benefits, we also need to consider the effects of exposure to these chemicals on following experimental studies. Exposure to any chemicals during transport, which induce an altered physiological state in the fish could have concomitant effects on experimental results. Therefore, an understanding of physiological effects and clearance/recovery rates of any chemicals used during transport is needed.

Once fishes arrive at the laboratory, it is important to avoid a sudden change in water quality when they are introduced into a new experimental system. Common arrival protocols involve slowly mixing system water with the water the fish are transported in over a period of time. Prior to experiments starting, fishes need to be given sufficient time to recover from the stress of transport during which time they are closely monitored for any signs of ill-health or abnormal behaviours. Quarantine periods should be considered, particularly when new fishes will be added to recirculating systems containing existing stock.

\section{Quality of Water and Food}

It is accepted that fishes require good water quality for good health; fishes are in direct contact with the water and deviations from appropriate water quality can quickly lead to health deterioration. Some of the main concerns over water quality are discussed above in relation to transport. The diversity of waters that fishes inhabit is astounding, including ionpoor acidic waters of the Amazon and high salinity and high alkalinity lakes. Thus it is vital to understand the requirements of the species being worked with; in the case of wild caught fishes, the water chemistry of their natural environment may need to be replicated in the laboratory. The optimal $\mathrm{pH}$ in which to keep freshwater fishes can range from 5.0 to 10.0 (Portz et al., 2006). Generally speaking, oxygen, temperature, $\mathrm{pH}$ and salinity are the key parameters of importance and the build-up of waste products such as ammonia, nitrite and nitrate requires monitoring as all can quickly reach toxic levels (Matthews, 2004; Stevens et al., 2017). Tank materials may also alter water quality, and care must be taken to avoid materials which leach harmful chemicals into the water. Unhealthy fishes will of course not provide robust scientific data. Reporting of water parameters and ranges allows other researchers to ensure that fishes were held in optional conditions and can often help in comparisons between laboratories. Water parameters that can change very quickly $(\mathrm{pH}$, temperature, DO) are usually monitored frequently (e.g. daily), while in an established 
aquarium water parameters which are slower to change (ammonia, nitrate, nitrite) may be monitored less frequently (e.g. weekly). There are automated ways of monitoring water quality available (e.g. www.seneye.com) which are increasing in popularity and allow for more frequent monitoring and faster response to suboptimal conditions.

Poor water quality often leads to outbreaks of disease. Acute outbreaks of disease cause obvious detriment to welfare and chronic disease conditions, particularly those which may go unnoticed for a period of time, may confound research results (Kent et al., 2008). The majority of research into fish diseases has focused on aquaculture species, and until recently research into diseases of other common research species was lacking. Common diseases of zebrafish have received the most attention and include systemic and dermal bacterial infections, mycobacteriosis, microsporidiosis and Ichthyophthirius infections (Matthews, 2004). Mycobacteriosis is the most commonly researched disease of warm-water research species with different species of Mycobacterium exhibiting different levels of virulence (Kent et al., 2008). Indeed Mycobacterium is often found in fishes in the absence of disease (Beran et al., 2006). Strategies for avoiding introduction of pathogens to research facilities put forward by Kent et al. (2008) include sourcing pathogen-free fishes, quarantining new stock, prophylactic treatment with therapeutic agents, avoiding introduction of contaminated water or food and using eggs only for new stock. Routine monitoring and culling of moribund, old or anorexic fishes may help prevent spread of chronic diseases.

While water quality as a factor in fish welfare is well recognised, less attention has been paid to the importance of diet for welfare. This is perhaps surprising given that nutritional deficiencies are likely to cause stress and affect disease resistance (Oliva-Teles, 2012). The natural diet of fishes is incredibly diverse and yet most commercial fish diets were originally formulated for aquaculture, and are aimed at carnivorous species of fish with requirements of up to $50 \%$ protein and $20 \%$ lipid (Halver \& Hardy, 2002). While some fish food manufacturers will take into account the different requirements of particular fish species, most commercially available diets are unlikely to be suitable for all fish species (O'Brine $e t$ $a l ., 2015)$. Additionally, in their natural environment fishes can show seasonal changes in food intake which is rarely considered under laboratory conditions. Live food may be given to experimental fishes (Lawrence, 2007) and can count as enrichment (see Quality of Housing 
below) but there are ethical issues with feeding live vertebrate prey (e.g. fishes) (see Table 2). The potential for live foods to act as vectors for pathogenic organisms is also an important consideration (Watts et al., 2016).

Feeding fishes a diet with a protein level higher than required can result in excess ammonia production and therefore decreased water quality (Ballestrazzi et al., 1994; Yang et al., 2002) and feeding fishes a diet with the wrong type or content of lipid can lead to reduced growth (Watanabe, 1982; Oliva-Teles, 2012). While most commercial diets contain sufficient vitamins and minerals for healthy growth, some forms of diet may leach vitamins into the water if they are not consumed immediately (Pannevis \& Earle, 1994). In comparison with mammalian work, it is notable that no standardised diet for model fish species exists. For example, very little is known about zebrafish nutrition and yet it is one of the most widely used fish models of human health and disease (Lawrence, 2007; Watts et al., 2016). Variability in diets across zebrafish labs, in addition to variable feeding frequencies, has the potential to influence experimental repeatability, and was recently identified as one of the most critical areas for refinement of D. rerio care (Lidster et al., 2017).

\section{Quality of Housing}

Correct water quality parameters and a nutritious diet will likely maintain health, but if we strive to allow fishes to perform more natural behaviours when in captivity then we need to consider how they are housed. Housing conditions in terms of tank design and water flow must be considered relative to the species, a subject which has been extensively reviewed by Portz et al. (2006). The great difficulties associated with defining 'natural behaviours' for fish species, particularly those that are under-researched, has been documented many times previous (Huntingford \& Kadri, 2008), along with the idea that animals bred in captivity may have altered 'natural' behavioural phenotypes compared to wild caught animals (Duncan \& Fraser, 1997). Nevertheless, there are several considerations which must be applied here. 
There are a variety of circumstances under which fishes may be held for research purposes. Breeding colonies for fishes such as zebrafish are common-place where complete life-cycles are held within the laboratory. Other fish species, such as salmonids, are more commonly purchased as juveniles and held only for a part of their life-cycle. The presence of stock tanks, where fishes are usually held before being transferred to experimental tanks is usual, and it is not unusual for the housing conditions to be different between stock and experimental tanks. When considering housing of fishes for research, the two factors which have received most attention are stocking density and environmental enrichment. Both are important not only from an ethical standpoint to ensure welfare is maximised, but also because they have the potential to alter the behaviour and physiology of the fish with consequences for scientific data collected.

The effects of stocking density on salmonid welfare have been reviewed extensively, particularly in relation to aquaculture (e.g. Ellis et al., 2002) where high densities can reduce growth and increase fin erosion. Low densities, on the other hand, can lead to excessive aggressive behaviour (Ellis et al., 2002), and the establishment of dominance hierarchies (Turnbull et al., 2005) with the potential for increased aggression and physiological consequences (Sloman \& Armstrong, 2000). Appropriate stocking densities for other species requires species-specific knowledge and particular attention must be paid to stocking densities where fish are sequentially removed during the course of the experiment, thus providing variable stocking densities. Levels of aggressive behaviour will also be species and life-stage specific. In zebrafish, stocking density has the potential to affect sex determination with higher stocking densities producing greater prevalence of males (Ribas et al., 2017). Other husbandry factors which can influence sex determination in zebrafish include temperature, hypoxia and food ration (Santos et al., 2017).

Näslund \& Johnson (2014) define environmental enrichment in their comprehensive review of fish enrichment techniques as "a deliberate increase in environmental complexity with the aim to reduce maladaptive and aberrant traits in fish reared in otherwise stimuli-deprived environments." Environmental enrichment for fishes, is usually an increase in structural complexity, but also for fishes commonly includes dietary enrichment (Brown et al., 2003) and social enrichment. For animals kept in captivity the EU directive on the protection of 
animals used for scientific purposes (EU, 2010) recommends enrichment such as hiding places or bottom substrate but recognises that this needs to be considered on a species by species basis. The addition of enrichment to tanks is often done to improve welfare, but the evidence that environmental enrichment promotes welfare in fishes is controversial, with many effects being species-specific (Kistler et al., 2011). In a recent survey of zebrafish facilities, less than $25 \%$ of facilities used environmental enrichment in the form of plants or substrate and were not considered practical by many of the laboratories surveyed (Lidster et al., 2017). Motivational and/or preference tests are often used and can indicate if a species values the presence of enrichment (e.g. Sullivan et al., 2015). Value may also vary depending on stocking density and species composition (Sloman et al., 2011). For a list of types of enrichment in relation to the types of species that may benefit, see Table 2 in Williams et al. (2009).

One of the most common structural enrichments for fish tanks is the addition of a shelter, or an area of vegetation, particularly to stock tanks. These provide places to hide and can allow individuals to escape from conspecific aggression. In salmonid species, the addition of physical enrichment can reduce basal plasma cortisol (Näslund et al., 2013) and aid recovery from a stressful event (Pounder et al., 2016). Physiological benefits such as forebrain cell proliferation have been associated with enrichment (Kihslinger \& Nevitt, 2006; von Krogh et al., 2010), and the presence of enrichment has been linked to increased learning in some species (Strand et al., 2010; Carbia \& Brown, 2019) but not others (Brydges \& Braithwaite, 2009). Therefore, it becomes important for research purposes, not only to consider whether enrichment is positive for welfare, but also any differences in physiology that result from enriched versus barren holding conditions.

Another type of structural enrichment includes the addition of substrate, such as sand or gravel, which has been shown to increase foraging behaviour in goldfish (Smith \& Gray, 2011). Batzina \& Karakatsouli (2012) found that gilthead seabream Sparus aurata L. 1758 grew better and were less aggressive with blue or red/brown glass gravel, compared with control (no gravel) or green glass. Benefits of substrate enrichment have been noted in flatfishes (McVicar, 1987; Ellis et al., 1997; Ottesen et al., 2007). However, one of the major drawbacks to the use of substrate, and also other physical structures, is the potential for 
pathogenic bacteria to grow on the increased surface area, although this has not been extensively researched (Tuckey \& Smith, 2001). Batzina \& Karakatsouli (2012) found higher water nitrite levels in tanks with substrate, which they potentially attributed to the increased substrate-particle surface area facilitating retention of fish waste products. These potential negative effects of environmental enrichment warrant further attention.

There are also concerns with the use of enrichment for toxicity trials, as the nature of regulatory test guidelines is such that many common forms of aquatic enrichment are not possible (Williams et al., 2009). If the guidelines are not met the study is considered invalid. For toxicity tests, microbial growth can break down chemicals in the water and microbial growth itself may be promoted by the addition of solvents used to dissolve the test chemical (Williams et al., 2009). An additional problem with enrichment in toxicity testing is that some types of material will adsorb chemicals, meaning fishes are not exposed to a constant concentration and some forms of enrichment may leach chemicals into the water. A small amount of research has considered appropriate forms of environment enrichment for fishes during toxicity trials (Wilkes et al., 2012) but this is clearly something that warrants further attention.

There are some important questions regarding the methods of housing fishes for experimental work which we believe are still often over-looked and require more thorough investigation. Often, only brief mention of the conditions in which stock fishes are held are provided in scientific manuscripts and yet these conditions are likely to influence scientific results found. The ARRIVE guidelines suggest that information on both housing and husbandry conditions should be provided; we suggest that this should be for both stocking and experimental conditions. Indeed, providing information on why enrichment was not used for a particular species or life-stage can be useful to other researchers in planning their experiments. Researchers should consider in particular, how the transfer of animals from stocking conditions to experimental conditions may alter the physiology or behaviour of their experimental animals and also whether each 'replicate' animal receives the same treatment. For example, if stock tanks contain environmental enrichment but experimental tanks do not, does this change in habitat complexity induce stress prior to the start of an experiment? 
1013 Once within an experimental system, there are a variety of different scientific procedures which a fish may be exposed to, and as discussed above, the effects of these protocols must always be weighed against the scientific advancement that they provide. It is not possible here to cover all of the different procedures, and many will vary from experiment to experiment, but ethical considerations of some of the most common scientific procedures used on fishes are given in Table 2 .

Field Studies

1021

1022

Non-invasive field observations

1023

1024

Snorkelling or SCUBA diving are often used for observing fish behaviour or conducting visual census along with video recordings. Although generally considered non-invasive, there may be instances when the presence of divers or equipment has the potential to alter natural behaviours and minimising the impact of these types of surveys on the environment should be prioritised. The effects of flash photography where still images are used for individual identification has also been tested in some species (Harasti \& Gladstone, 2013). Whether direct observation or video is more appropriate may depend on the behaviours being analysed (Branconi et al., 2019).

Baited remote underwater video surveys (BRUVS)

Baited remote underwater video surveys (BRUVS) are a non-invasive alternative to fishing surveys for generating relative abundance indices (Brooks et al., 2011b; Whitmarsh et al., 2017; Sherman et al., 2018). The efficacy of BRUVS in generating relative abundance indices has been validated against many traditional fishing gears, suggesting that BRUVS produce comparable estimates under certain circumstances (Brooks et al., 2011b; Santana- 
Garcon et al., 2014; McLean et al., 2015). In general, BRUVS are considered to have minimal negative impacts on the target population, sampling location, or environment (Whitmarsh et al., 2017). Furthermore, BRUVS can be more resource efficient and cost effective per replicate than maintaining fishing surveys, can detect animals that would otherwise be excluded by the selectivity of fishing gears, and generate a permanent record of fishes present including an ethogram of behaviours (Brooks et al., 2011b; Kilfoil et al., 2017). The use of BRUVS is not without shortcomings. Baiting will alter the behaviour of fishes and in extreme cases, inter- and intraspecific competition for the bait lead to agonistic interactions between animals (O'Shea et al., 2015). Possible abrasions from fishes bumping into the BRUVS unit or bait bag/box may cause minimal harm and larger fishes (e.g. sharks) may be able to remove, ingest, or retain part of the BRUVS unit (Brooks et al., 2011b). Nevertheless, BRUVS are considerably less invasive relative to fishing techniques and their use to survey wild fish populations, from coral reefs to the deep sea, has become commonplace over the past 20 years (Whitmarsh et al., 2017).

\section{Catch and release of wild animals}

The capture of wild animals is an inherently stressful process and techniques to mitigate stress and mortality have received much attention in fishes. The perception of a threat upon capture can induce a stress response in the form of increased levels of circulating stress hormones (catecholamines and corticosteroids), and exercise associated with struggling during capture can induce a physiological response of metabolic (e.g. accumulation of lactic acid) and/or respiratory (e.g. accumulation of $\mathrm{CO}_{2}$ ) origin (Wood, 1991; Wendelaar Bonga, 1997). Handling fishes after capture can cause further stress; the duration and nature of handling (e.g. how long fishes are held out of water) can affect the stress response (Gingerich et al., 2007; Cook et al., 2015). Collecting fishes in extreme conditions (e.g. high water temperatures, low dissolved oxygen), or exposing fishes to extreme environmental gradients (e.g. temperature and pressure change from capture at depth) can also have physiological consequences (Pankhurst, 2011; Wilson et al., 2014; Talwar et al., 2017). Physiological stress associated with capture may ultimately be sufficient to induce immediate or post-release mortality for some species (Wood et al., 1983). 
Fishes can experience physical injury during capture and handling. Foul-hooking or ingesting hooks can be quite serious; the risk of these injuries can be minimized by modifying fishing gear, such as switching from "J" hooks to circle hooks (Skomal et al., 2002; Reinhardt et al., 2018). Depending on the nature of the injury, a fish should either be released immediately to minimize additional handling stress, or euthanised (Fobert et al., 2009). Some species, however, are demonstrably resilient to injuries (Chin et al., 2015; Kessel et al., 2017). Physical injuries (e.g. scale loss or cuts) can also arise from entanglement and abrasion, crushing injuries from net fishing gears, and barotrauma following rapid ascent; severe injuries can quickly lead to critical failure of vital tissues (Cook et al., 2019).

Captured fishes are unable to escape predators and can also be rendered unable to do so upon release. Indeed, depredation is a serious issue to consider for catch and release of wild fishes (Raby et al., 2014). Techniques to recover captured fishes in recreational and commercial fisheries have been validated for many fisheries (Brownscombe et al. 2017a; Cook et al. 2019), such as retaining fishes to allow partial or full recovery to improve condition, performance, and the odds of survival upon release (Farrell et al., 2001; Suski et al., 2007; Brownscombe et al., 2013). However, some techniques previously thought to improve condition (e.g., assisted ventilation) may be of little benefit in some species or given the context-specific nature of capture (Brownscombe et al., 2017b; Cook et al. 2019). The chronic effects associated with stressful events are receiving considerable attention in fishes, with the overall body of research suggesting that a fish that survives capture to be released may take hours to days to resume normal behaviour and physiology (Kieffer, 2000; Wilson et al., 2014). The best recommendations from the available literature for mitigating a fish's stress response resulting from capture are to minimize capture and handling duration, and to minimize the duration of air exposure (Cooke et al., 2013; Cook et al., 2019). Indeed, social programs have even been developed to encourage anglers to follow these simple "bestpractice" guidelines, such as handling fishes in the water (Danylchuk et al., 2018).

Field studies must also account for the capture of non-target species, i.e. bycatch. Gear and technique modifications can improve the selectivity of fishing gear to minimize bycatch. Physical attributes of gear, including the timing and location of fishing, can affect the likelihood of encountering bycatch species. For instance, hook type and size can have effects 
on capture rates of certain species (Reinhardt et al., 2018). In addition, fishing depth, bait, time of day, season, and environmental conditions (e.g. sea surface temperature) can all influence the likelihood of encountering bycatch (Watson \& Kerstetter, 2006). Implementing bycatch reduction devices can (theoretically) reduce the incidence of bycatch species without affecting that of the target species (Jordan et al., 2013). Some studies, for example, have tested the efficacy of devices generating electromagnetic fields to deter electroreceptive fishes (O’Connell \& He, 2014). It should be noted that fishing in aquatic environments can attract more than just fish bycatch; avian, reptilian, and possibly mammalian bycatch must also be considered (Lewison et al., 2004).

The combined effects of capture, handling, and environmental conditions must be considered when choosing the best methods to ensure high post-release survivorship (PRS) during catchand-release fishing. Fortuitously, determining the magnitude of physiological stress experienced by the target species using a given fishing gear can be assessed using simple assays and commercially available equipment (Cooke et al., 2013; Madliger et al., 2018). Simple phlebotomy techniques paired with species-validated point-of-care analytical devices can provide insights into an animal's physiological status (e.g. whole-blood acid-base status or metabolite concentrations) within minutes of blood sampling (Stoot et al., 2014).

Similarly, simple behavioural indices, such as reflexes to various stimuli (e.g. a vigorous escape when released or inducing a biting response) can be powerful predictors of an animal's PRS (Davis, 2010). As such, advances in field-based behaviour and physiology studies of fishes have revealed simple diagnostic techniques that can be introduced to a study to improve confidence that animals are being returned to the wild in a condition that will not compromise their survival.

\section{CONCLUSION}

Most fish biologists share the consensus that it is the best interests of their research that the fishes they work with are not stressed, are healthy and that their welfare is carefully considered, regardless of whether or not they believe fishes can experience pain. Definitions of welfare spark controversy, yet again there is much consensus in suggested measures. 
Regardless of these controversies, improved ethics and welfare of fishes, almost inevitably results in improved scientific rigour as it challenges us to think about the natural habitat and life histories of the species we work with. Current dilemmas facing fish researchers include when to use anaesthetics, whether to use analgesics and the lack of a standardised diet for many laboratory-held species. Many non-significant results go unreported and many studies fail to provide sufficient information on how fishes were treated.

Regulations and guidelines can differ quite dramatically from country to country, with what is acceptable for one fish researcher considered an illegal practice for another. There is similar inconsistency in the prominence of ethical consideration by fish-related academic journals. Here there seems to be capacity for journals to contribute to improved welfare through education, debate and careful consideration of ethical requirements. The emphasis on fish welfare both out-with and amongst the scientific community seems unlikely to wane and it is in our best interest to strive to refine our research practices both for the fishes and environments we work with and for our scientific outcomes.

\section{Acknowledgements}

The authors would like to thank three anonymous reviewers and Myriam Vanderzwalmen for their thoughtful comments on previous drafts.

\section{$\underline{\text { References }}$}

Abbas, R. \& Hayton, W.L. (1997). A physiologically based pharmacokinetic and pharmacodynamics model for paraoxon in rainbow trout. Toxicology and Applied Pharmacology 145, 192-201.

Adams, N.S., Rondorf, D.W., Evans, S.D., Kelly, J.E. \& Perry, R.W. (1998). Effects of surgically and gastrically implanted radio transmitters on swimming performance and predator avoidance of juvenile chinook salmon (Oncorhynchus tshawytscha). Canadian Journal of Fisheries and Aquatic Sciences 55, 781-787.

Aiello, B.R., Stewart, T.A. \& Hale, M.E. (2016). Mechanosensation in an adipose fin. Proceedings of the Royal Society B 283, 20152794.

AFS (2014). Use of Fishes in Research Committee (joint committee of the American Fisheries Society, the American Institute of Fishery Research Biologists, and the American Society of Ichthyologists and Herpetologists) (2014). Guidelines for the use of fishes in research. American Fisheries Society, Bethesda, Maryland. 
Amend, D.F., Croy, T.R., Goven, B.A., Johnson, K.A. \& McCarthy, D.H. (1982). Transportation of fish in closed systems: methods to control ammonia, carbon dioxide, $\mathrm{pH}$, and bacterial growth. Transactions of the American Fisheries Society 111, 603611.

Animal Sentience (2016). http://animalstudiesrepository.org/animsent/vol1/iss3/

Arlinghaus, R., Cooke, S.J., Schwab, A. \& Cowx, I.G. (2007). Fish welfare: a challenge to the feelings based approach, with implications for recreational fishing. Fish and Fisheries 8, 57-71.

ASAB (2012). Guidelines for the treatment of animals in behavioural research and teaching. Animal Behaviour 83, 301-309.

ASAB (2018). Guidelines for the treatment of animals in behavioural research and teaching. Animal Behaviour 135, in press.

ASPA (2013). https://assets.publishing.service.gov.uk/government/uploads/system/uploads/attachment _data/file/619140/ConsolidatedASPA1Jan2013.pdf

Ashley, P.J., Sneddon, L.U. \& McCrohan, C.R. (2006). Properties of corneal receptors in teleost fish. Neuroscience Letters 410, 165-168.

Ashley, P.J., Sneddon, L.U. \& McCrohan, C.R. (2007). Nociception in fish: stimulusresponse properties of receptors on the head of trout Oncorhynchus mykiss. Brain Research 1166, 47-54.

Ashley, P.J., Ringrose, S., Edwards, K.L., McCrohan, C.R. \& Sneddon, L.U. (2009). Effect of noxious stimulation upon antipredator responses and dominance status in rainbow trout. Animal Behaviour 77, 403-410.

AVMA (2007). https://grants.nih.gov/grants/olaw/Euthanasia2007.pdf

Baker, T.R., Baker, B.B., Johnson, S.M. \& Sladky, K.K. (2013). Comparative analgesic efficacy of morphine sulfate and butorphanol tartrate in koi (Cyprinus carpio) undergoing unilateral gonadectomy. JAVMA-Journal of The American Veterinary Medical Association 243, 882-890.

Ballestrazzi, R., Lanari, D., D’Agaro, E. \& Mion, A. (1994). The effect of dietary protein level and source on growth, body composition, total ammonia and reactive phosphate excretion of growing sea bass (Dicentrarchus labrax). Aquaculture 127, 197-206.

Balzarini, V., Taborsky, M., Wanner, S., Koch, F.\& Frommen, J.G. (2014). Mirror, mirror on the wall: the predictive value of mirror tests for measuring aggression in fish. Behaviour Ecology and Sociobiology 68, 871-878.

Bangs, B.L., Falcy, M.R., Scheerer, P.D. \& Clements, S. (2013). Comparison of three methods for marking a small floodplain minnow. Animal Biotelemetry 1, 18.

Barton, B.A. (2002). Stress in fishes: a diversity of responses with particular reference to changes in circulating corticosteroids. Integrative and Comparative Biology 42, 517525.

Bateson, P. (1991). Assessment of pain in animals. Animal Behaviour 42, 827-839.

Batzina, A. \& Karakatsouli, N. (2012). The presence of substrate as a means of environmental enrichment in intensively reared gilthead seabream Sparus aurata: Growth and behavioral effects. Aquaculture 370-371, 54-60.

Bauer, C. \& Loupal, G. (2007). Common carp tissue reactions to surgically implanted radio tags with external antennas. Journal of Fish Biology 70, 292-297.

Belanger, S.E., Rawlings, J.M. \& Carr, G.J. (2013). Use of fish embryo toxicity tests for the prediction of acute fish toxicity to chemicals. Environmental Toxicology and Chemistry 32, 1768-1783. 
Bennett, R.H., Ellender, B.R., Mäkinen, T., Miya, T., Pattrick, P., Wasserman, R.J., Woodford, D.J. \& Weyl, O.L.F. (2016). Ethical considerations for field research on fishes. Koedoe 58, a1353.

Beran, V., Matlova, I., Dvorska, L., Svastova, P.\& Palik, I. (2006). Distribution of mycobacteria in clinically healthy ornamental fish and their aquarium environment. Journal of Fish Diseases 29, 383-393.

Block, B.A., Jonsen, I.D., Jorgensen, S.J., Winship, A.J., Shaffer, S.A., Bograd, S.J., Hazen, E.L., Foley, D.G., Breed, G.A., Harrison, A.L., Ganong, J.E., Swithenbank, A., Castleton, M., Dewar, H., Mate, B.R., Shilinger, G.L., Schaefer, K.M., Benson, S.R., Weise, M.J., Henry, R.W. \& Costa, D.P. (2011). Tracking apex marine predator movements in a dynamic ocean. Nature 475, 86-90.

Bols, N.C., Dayeh, V.R., Lee, L.E.J. \& Schirmer, K. (2005). Use of fish cell lines in the toxicology and ecotoxicology of fish. Piscine cell lines in environmental toxicology. Biochemistry \& Molecular Biology of Fishes 6, 43-84.

Bopp, S.K., Abicht, H.K. \& Knauer, K. (2008). Copper-induced oxidative stress in rainbow trout gill cells. Aquatic Toxicology 86, 197-204.

Bouyoucos, I.A., Suski, C.D., Mandelman, J.W. \& Brooks, E.J. (2017). Effect of weight and frontal area of external telemetry packages on the kinematics, activity levels and swimming performance of small-bodied sharks. Journal of Fish Biology 90, 20972110 .

Branconi, R., Wong, M.Y.L. \& Buston, P.M. (2019). Comparison of efficiency of direct observations by SCUBA diver and indirect observations via video camera for measuring reef fish behaviour. Journal of Fish Biology in press.

Breacker, C., Barber, I., Norton, W.H.J., McDearmid, J.R. \& Tilley, C.A. (2017). A low-cost method of skin swabbing for the collection of DNA samples from small laboratory fish. Zebrafish 14, 35-41.

Brix, K.V., DeForest, D.K., Tear, L., Grosell, M. \& Adams, W.J. (2017). Use of multiple linear regression models for setting water quality criteria for copper: A complimentary approach to the Biotic Ligand Model. Environmental Science \& Technology 51, 51825192.

Brooks, E.J., Sloman, K.A., Liss, S., Hassan-Hassanein, L., Danylchuk, A.J., Cooke, S.J., Mandelman, J.W., Skomal, G.B., Sims, D.W. \& Suski, C.D. (2011a). The stress physiology of extended duration tonic immobility in the juvenile lemon shark, Negaprion brevirostris (Poey 1868). Journal of Experimental Marine Biology and Ecology 409, 351-360.

Brooks, E., Sloman, K., Sims, D. \& Danylchuk, A. (2011b). Validating the use of baited remote underwater video surveys for assessing the diversity, distribution and abundance of sharks in the Bahamas. Endangered Species Research 13, 231-243.

Broom, D. M. (2007). Cognitive ability and sentience: which aquatic animals should be protected? Diseases of Aquatic Animals 75, 99-108.

Broom, D.M. (2014). Sentience and Animal Welfare. 185 pp. Wallingford: CABI International.

Browman, H.I., Cooke, S.J., Cowx, I.G., Derbyshire, S.W.G., Kasumyan, A., Key, B., Rose, J.D., Schwab, A., Skiftesvik, A.B., Stevens, D., Watson, C.A. \& Arlinghaus, R. (2018). Welfare of aquatic animals: where things are, where they are going, and what it means for research, aquaculture, recreational angling, and commercial fishing. ICES Journal of Marine Science in press.

Brown, C. (2015). Fish intelligence, sentience and ethics. Animal Cognition 18, 1-17. 
Brown, C., Davidson, T. \& Laland, K. (2003). Environmental enrichment and prior experience of live prey improve foraging behaviour in hatchery-reared Atlantic salmon. Journal of Fish Biology 63, 187-196.

Brown, C. \& Laland, K. (2001). Social learning and life skills training for hatchery reared fish. Journal of Fish Biology 59, 471-493.

Brown, R.S., Cooke, S.J., Anderson, W.G. \& McKinley, R.S. (1999). Evidence to challenge the " $2 \%$ Rule" for biotelemetry. North American Journal of Fisheries Management 19, 867-871.

Brownscombe, J.W., Thiem, J.D., Hatry, C., Cull, F., Haak, C.R., Danylchuk, A.J. \& Cooke, S.J. (2013). Recovery bags reduce post-release impairments in locomotory activity and behavior of bonefish (Albula spp.) following exposure to angling-related stressors. Journal of Experimental Marine Biology and Ecology 440, 207-215.

Brownscombe, J.W., Parmar, T.P., Almeida, J., Giesbrecht, E., Batson, J., Chen, X., Wesch, S., Ward, T.D., O'Connor, C.M. \& Cooke, S.J. (2017b). The efficacy of assisted ventilation techniques for facilitating the recovery of fish that are exhausted from simulated angling stress. Fisheries Research 186, 619-624.

Brownscombe, J.W., Danylchuk, A.J., Chapman, J.M., Gutowsky, L.F. \& Cooke, S.J. (2017a). Best practices for catch-and-release recreational fisheries - angling tools and tactics. Fisheries Research 186, 693-705.

Brunnschweiler, J.M. (2009). Tracking free-ranging sharks with hand-fed intra-gastric acoustic transmitters. Marine and Freshwater Behavior and Physiology 42, 201-209.

Brydges, N.M. \& Braithwaite, V.A. (2009). Does environmental enrichment affect the behaviour of fish commonly used in laboratory work? Applied Animal Behaviour Science 118, 137-143.

Buckland-Nicks, J.A. (2016). New details of the neural architecture of the salmonid adipose fin. Journal of Fish Biology 89, 1991-2003.

Buckland-Nicks, J.A., Gillis, M. \& Reimchen, T.E. (2012). Neural network detected in a presumed vestigial trait: ultrastructure of the salmonid adipose fin. Proceedings of the Royal Society B 279, 553-563.

Campanella, J.J. \& Smalley, J.V. (2006). A minimally invasive method of piscine tissue collection and an analysis of long-term field-storage conditions for samples. $B M C$ Genetics 7, 32.

Carbia, P.S. \& Brown, C. (2019). Environmental enrichment influences spatial learning ability in captive-reared intertidal gobies (Bathygobius cocosensis). Animal Cognition 22, 89-98.

Champagne, C.E., Austin, J.D., Jelks, H.L. \& Jordan, F. (2008). Effects of fin clipping on survival and position-holding behaviour of brown darters, Etheostoma edwini. Copeia 2008, 916-919.

Chandroo, K.P., Duncan, I.J.H. \& Moccia, R.D. (2004). Can fish suffer?: perspectives on sentience, pain, fear and stress. Applied Animal Behaviour Science 86, 225-250.

Chervova, L.S. (1997). Pain sensitivity and behavior of fishes. Journal of Ichthyology 37, 98102.

Chervova, L.S. \& Lapshin, D.N. (2000). Opioid modulation of pain threshold in fish. Doklady Biological Sciences 375, 590-591.

Chervova, L.S., Lapshin, D.N. \& Kamenskii, A.A. (1994). Pain sensitivity of trout and analgesia induced by intranasal administration of dermorphine. Doklady Biological Sciences 338, 424-425.

Chin, A., Mourier, J. \& Rummer, J.L. (2015). Blacktip reef sharks (Carcharhinus melanopterus) show high capacity for wound healing and recovery following injury. Conservation Physiology 3, cov062. 
Cho, G.K. \& Heath, D.D. (2000). Comparison of tricaine methanesulphonate (MS222) and clove oil anaesthesia effects on the physiology of juvenile chinook salmon Oncorhynchus tshawytscha (Walbaum). Aquaculture Research 31, 537-546.

Clark, T.D., Furey, N.B., Rechisky, E.L., Gale, M.K., Jeffries, K.M., Porter, A.D., Casselman, M.T., Lotto, A.G., Patterson, D.A., Cooke, S.J., Farrell, A.P., Welch, D.W. \& Hinch, S.G. (2016). Tracking wild sockeye salmon smolts to the ocean reveals distinct regions of nocturnal movement and high mortality. Ecological Applications 26, 959-978.

Cook, K.V., Lennox, R.J., Hinch, S.G. \& Cooke, S.J. (2015). Fish out of water: How much air is too much? Fisheries 40, 452-461.

Cook, K.V, Reid, A.J., Patterson, D.A., Robinson, K.A., Chapman, J.M., Hinch, S.G. \& Cooke, S.J. (2019). A synthesis to understand responses to capture stressors among fish discarded from commercial fisheries and options for mitigating their severity. Fish and Fisheries 20, 25-43.

Cooke, S.J. (2016). Spinning our wheels and deepening the divide: Call for an evidencebased approach to the fish pain debate. Animal Sentience 3(42).

Cooke, S.J., Hinch, S.G., Wikelski, M., Andrews, R.D., Kuchel, L.J., Wolcott, T.G. \& Butler, P.J. (2004). Biotelemetry: A mechanistic approach to ecology. Trends in Ecology and Evolution 19, 334-343.

Cooke, S.J., Crossin, G.T., Patterson, D.A., English, K.K., Hinch, S.G., Young, J.L., Alexander, R.F., Healey, M.C., Kraak, G. van der \& Farrell, A.P. (2005). Coupling non-invasive physiological assessments with telemetry to understand inter-individual variation in behaviour and survivorship of sockeye salmon: development and validation of a technique. Journal of Fish Biology 67, 1342-1358.

Cooke, S. J., Hinch, S. G., Donaldson, M. R., Clark, T. D., Eliason, E. J., Crossin, G. T., Raby, G. D., Jeffries, K. M., Lapointe, M., Miller, K., Patterson, D.A. \& Farrell, A.P. (2012). Conservation physiology in practice: How physiological knowledge has improved our ability to sustainably manage Pacific salmon during up-river migration. Philosophical Transactions of the Royal Society of London. Series B, Biological Sciences 367, 1757-1769.

Cooke, S.J., Donaldson, M.R., O’Connor, C.M., Raby, G.D., Arlinghaus, R., Danylchuk, A.J., Hanson, K.C., Hinch, S.G., Clark, T.D., Patterson, D.A. \& Suski, C.D. (2013). The physiological consequences of catch-and-release angling: perspectives on experimental design, interpretation, extrapolation and relevance to stakeholders. Fisheries Management and Ecology 20, 268-287.

Cooke, S.J., Wilson, A.D.M., Elvidge, C.K., Lennox, R.J., Jepsen, N., Colotelo, A.H. \& Brown, R.S. (2016a). Ten practical realities for institutional animal care and use committees when evaluating protocols dealing with fish in the field. Reviews in Fish Biology and Fisheries 26, 123-133.

Cooke, S.J., Brownscombe, J.W., Raby, G.D., Broell, F., Hinch, S.G., Clark, T.D. \& Semmens, J.M. (2016b). Remote bioenergetics measurements in wild fish: Opportunities and challenges. Comparative Biochemistry and Physiology A 202, 23-37.

Conte, F.S. (2004). Stress and the welfare of cultured fish. Applied Animal Behaviour Science 86, 205-223.

Correia, A.D., Cunha, S.R., Scholze, M. \& Stevens, E.D. (2011a). A novel behavioral fish model of nociception for testing analgesics. Pharmaceuticals 4, 665-680.

Correia, J.P.S., Graça, J.T.C., Hirofumi, M. \& Kube, N. (2011b). Long-term transportation, by road and air, of chub mackerel (Scomber japonicas) and Atlantic bonito (Sarda sarda). Zoo Biology 30, 459-472. 
Costello, M.J., Beard, K.H., Corlett, R.T., Cumming, G.S., Devictor, V., Loyola, R., Maas, B., Miller-Rushing, A.J., Pakeman, R. \& Primack, R.B. (2016). Field work ethics in biological research. Biological Conservation 203, 268-271.

Curtright, A., Rosser, M., Goh, S., Keown, B., Wagner, E., Sharifi, J., Raible, D.W. \& Dhaka, A. (2015). Modeling nociception in zebrafish: a way forward for unbiased analgesic discovery. PLoS One 10, e0116766.

Curzer, H.J., Wallace, M., Perry, G., Muhlburger, P. \& Perry, D. (2013). Environmental research ethics. Environmental Ethics 35, 95-114.

Danylchuk, A.J., Danylchuk, S.C., Kosiarski, A., Cooke, S.J. \& Huskey, B. (2018) Keepemwet Fishing-An emerging social brand for disseminating best practices for catch-and-release in recreational fisheries. Fisheries Research 205, 52-56.

Davis, M.W. (2010). Fish stress and mortality can be predicted using reflex impairment. Fish and Fisheries 11, 1-11.

Davis, M.R., Mylniczenko, N., Storms, T., Raymond, F. \& Dunn, J.L. (2006). Evaluation of intramuscular ketoprofen and butorphanol as analgesics in chain dogfish (Scyliorhinus retifer). Zoo Biology 25, 491-500.

Dawkins, M.S. (1998). Evolution and animal welfare. Quarterly Review of Biology 73, 305328.

Dawkins, M.S. (2004). Using behaviour to assess animal welfare. Animal Welfare 13, 3-7.

Deters, K. A., Brown, R.S., Carter, K.M., Boyd, J.W. \& Eppard, M.B. (2010). Performance assessment of suture type, water temperature, and surgeon skill in juvenile Chinook salmon surgically implanted with acoustic transmitters. Transactions of the American Fisheries Society 139, 888-899.

Duncan, I.J.H. \& Fraser, D. (1997). Understanding animal welfare. In Animal Welfare (Appleby, M.C. \& Hughes, B.O., eds), pp. 19-31. Wallingford: CABI Publishing.

Dunlop, R. \& Laming, P. (2005). Mechanoreceptive and nociceptive responses in the central nervous system of goldfish (Carassius auratus) and trout (Oncorhynchus mykiss). Journal of Pain 6, 561-568.

Dunlop, R., Millsopp, S. \& Laming, P. (2006). Avoidance learning in goldfish (Carassius auratus) and trout (Oncorhynchus mykiss) and implications for pain perception. Applied Animal Behaviour Science 97, 255-271.

Dwan, K., Gamble, C., Williamson, P.R. \& Kirkham, J.J. (2013). Systematic review of the empirical evidence of study publication bias and outcome reporting bias- An updated review. PLOS ONE 8, e66844.

Ellis, T., Howell, B.R. \& Hughes, R.N. (1997). The cryptic responses of hatchery-reared sole to a natural sand substratum. Journal of Fish Biology 51, 389-401.

Ellis, T., North, B., Scott, A.P., Bromage, N.R., Porter, M. \& Gadd, D. (2002). The relationships between stocking density and welfare in farmed rainbow trout. Journal of Fish Biology 61, 493-531.

Elwood, R.W., Stoilova, V., McDonnell, A., Earley, R.L. \& Arnott, G. (2014). Do mirrors reflect reality in agonistic encounters? A test of mutual cooperation in displays. Animal Behaviour 97, 63-67.

EU Directive (2010). https://eur-lex.europa.eu/legalcontent/EN/TXT/?uri=CELEX\%3A32010L0063

European Commission (2017). Report Welfare of farmed fish: Common practices during transport and at slaughter SANTE/2016/G2/009, September 2017. https://ec.europa.eu/food/sites/food/files/animals/docs/aw_platform_20180621_pres05. pdf

Fanelli, D. (2010). Do pressures to publish increase scientists' bias? An empirical support from US States data. PLoS One 5, e10271. 
Farrell, A.P., Gallaugher, P.E., Fraser, J., Pike, D., Bowering, P., Hadwin, A.K.M., Parkhouse, W. \& Routledge, R. (2001). Successful recovery of the physiological status of coho salmon on board a commercial gillnet vessel by means of a newly designed revival box. Canadian Journal of Fisheries and Aquatic Sciences 58, 1932-1946.

Feltham, M.J. \& MacLean, J.C. (1996). Carlin tag recoveries as an indicator of predation on salmon smolts by goosanders and red-breasted mergansers. Journal of Fish Biology 48, 270-282.

Festing, M.F.W. \& Altman, D.G. (2002). Guidelines for the design and statistical analysis of experiments using laboratory animals. ILAR Journal 43, 244-258.

Flowers, K.I., Henderson, A.C., Lupton, J.L. \& Chapman, D.D. (2017). Site affinity of whitespotted eagle rays Aetobatus narinari assessed using photographic identification. Journal of Fish Biology 91, 1337-1349.

Fobert, E., Meining, P., Colotelo, A., O’Connor, C. \& Cooke, S.J. (2009). Cut the line or remove the hook? An evaluation of sublethal and lethal endpoints for deeply hooked bluegill. Fisheries Research 99, 38-46.

Froese, R. (1988). Relationship between body weight and loading densities in fish transport using the plastic bag method. Aquaculture and Fisheries Management 19, 275-281.

Frommen, J.G., Hanak, S., Schmidl, C.A. \& Thünken, T. (2015). Visible implant elastomer tagging influences social preferences of zebrafish (Danio rerio). Behaviour 152, 17651777.

Fu, C., Cao, Z.D. \& Fu, S.-J. (2013). The effects of caudal fin amputation on metabolic interaction between digestion and locomotion in juveniles of three cyprinid fish species with different metabolic modes. Comparative Biochemistry and Physiology A 164, 456465.

Gill, A.B. (2003). The dynamics of prey choice in fish: the importance for prey size and satiation. Journal of Fish Biology 63, 105-116.

Gingerich, A.J., Cooke, S.J., Hanson, K.C., Donaldson, M.R., Hasler, C.T., Suski, C.D. \& Arlinghaus, R. (2007). Evaluation of the interactive effects of air exposure duration and water temperature on the condition and survival of angled and released fish. Fisheries Research 86, 169-178.

Gräns, A., Sandblom, E., Kiessling, A. \& Axelsson, M. (2014). Post-surgical analgesia in rainbow trout: Is reduced cardioventilatory activity a sign of improved animal welfare or the adverse effects of an opioid drug? PLOS ONE 9, e95283.

Halver, J.E. \& Hardy, R.W. (2002). Fish Nutrition. San Diego, CA: Academic Press.

Harasti, D. \& Gladstone, W. (2013). Does underwater flash photography affect the behaviour, movement and site persistence of seahorses? Journal of Fish Biology 83, 1344-1353.

Harms, C.A., Lewbart, G.A., Swanson, C.R., Kishimori, J.M. \& Boylan, S.M. (2005). Behavioral and clinical pathology changes in koi carp (Cyprinus carpio) subjected to anesthesia and surgery with and without intra-operative analgesics. Comparative Medicine 55, 221-226.

Hart, P.J.B. (1997). Foraging tactics. In Behavioural Ecology of Teleost Fishes (Godin, J.G.J., ed.), pp. 104-133. Oxford: Oxford University Press.

Hawkins, P., Prescott, M.J., Carbone, L., Dennison, N., Johnson, C., Makowska, I.J., Marquardt, N., Readman, G., Weary, D. \& Colledge, H.D.R. (2016). A good death? Report of the second Newcastle meeting on laboratory animal euthanasia. Animals $\mathbf{6}$, E50.

Heupel, M.R. \& Simpendorfer, C.A. (2010). Science or slaughter: need for lethal sampling of sharks. Conservation Biology 24, 1212-1218.

Hohn, C. \& Petrie-Hanson, L. (2013). Evaluation of visible implant elastomer tags in zebrafish (Danio rerio). Biology Open 2, 1397-1401. 
Holland, K.N., Wetherbee, B.M., Lowe, C.G. \& Meyer, C.G. (1999). Movements of tiger sharks (Galeocerdo cuvier) in coastal Hawaiian waters. Marine Biology 134, 665-673. MS-222 on blood hormone profiles in rainbow trout Oncorhynchus mykiss, Walbaum. Aquaculture 35, 1025-1030.

Hoyle, I. \& Handy, R.D. (2005). Dose-dependent inorganic mercury absorption by isolated perfused intestine of rainbow trout, Oncorhynchus mykiss, involves both amiloridesensitive and energy-dependent pathways. Aquatic Toxicology 72, 147-159.

Huntingford, F.A., Adams, C., Braithwaite, F.A., Kadri, S., Pottinger, T.G., Sandøe, P. \& Turnbull, J.F. (2006). Current issues in fish welfare. Journal of Fish Biology 68, 332372.

Huntingford, F.A. \& Kadri, S. (2008). Welfare and fish. In Fish Welfare (Branson, E.J., ed.), pp.19-31. Oxford: Blackwell.

Huntingford, F.A., Borcato, F.L. \& Mesquita, F.O. (2013). Identifying individual common carp Cyprinus carpio using scale pattern. Journal of Fish Biology 83, 1453-1458.

Hussey, N. E., Kessel, S. T., Aarestrup, K., Cooke, S. J., Cowley, P. D., Fisk, A. T., Harcourt, R. G., Holland, K. N., Iverson, S. J., Kocik, J. F., Mills Flemming, J.E. \& Whoriskey, F.G. (2015). Aquatic animal telemetry: A panoramic window into the underwater world. Science 348, 1255642.

IASP, (1979) Pain, 6, 249-252.

Iwama, G.K., Pickering, A.D., Sumpter, J.P. \& Schreck, C.P. (1997). Fish Stress and Health in Aquaculture. Cambridge: Cambridge University Press.

Jepsen, N., Thorstad, E.B., Havn, T. \& Lucas, M.C. (2015). The use of external electronic tags on fish: an evaluation of tag retention and tagging effects. Animal Biotelemetry $\mathbf{3}$, 49-71.

Jones, S.G., Kamunde, C., Lemke, K. \& Stevens, E.D. (2012). The dose-response relation for the antinociceptive effect of morphine in a fish, rainbow trout. Journal of Veterinary Pharmacology and Therapeutics 35, 563-570.

Jordan, L.K., Mandelman, J.W., McComb, D.M., Fordham, S.V., Carlson, J.K. \& Werner T.B. (2013). Linking sensory biology and fisheries bycatch reduction in elasmobranch fishes: a review with new directions for research. Conservation Physiology 1, cot002.

Journal of Fish Biology (2006). Ethical justification for the use and treatment of fishes in research. Journal of Fish Biology 68, 1-2.

Kelly, W.H. (1967). Marking freshwater and a marine fish by injected dyes. Transactions of the American Fisheries Society 96, 163-175.

Kent, M.L., Feist, S.W., Harper, C., Hoogstraten-Miller, S., Law, J.M., Sánchez-Morgado, J.M., Tanguay, R.L., Sanders, G.E., Spitsbergen, J.M., Whipps, C.M. (2008). Recommendations for control of pathogens and infectious diseases in fish research facilities. Comparative Biochemistry and Physiology C 149, 240-248.

Kessel, S.T., Fraser, J., Bonn, W.G. van, Brooks, J.L., Guttridge, T.L., Hussey, N.E. \& Gruber, S.H. (2017). Transcoelomic expulsion of an ingested foreign object by a carcharhinid shark. Marine and Freshwater Research 68, 2173.

Kessel, S.T., Hussey, N.E. \& MacLatchey, D. (2015). Tonic immobility as an anaesthetic for elasmobranchs during surgical implantation procedures. Canadian Journal of Fisheries and Aquatic Sciences 72, 1287-1291.

Key, B. (2016) Why fish do not feel pain. Animal Sentience 1(1). http://animalstudiesrepository.org/animsent/vol1/iss3/1/

Kieffer, J.D. (2000). Limits to exhaustive exercise in fish. Comparative Biochemistry and Physiology A 126, 161-179. 
Kihslinger, R.L. \& Nevitt, G.A. (2006). Early rearing environment impacts cellular growth in juvenile salmon. Journal of Experimental Biology 209, 504-509.

Kilfoil, J., Wirsing, A., Campbell, M., Kiszka, J., Gastrich, K., Heithaus, M., Zhang, Y. \& Bond, M. (2017). Baited remote underwater video surveys undercount sharks at high densities: insights from full-spherical camera technologies. Marine Ecology Progress Series 585, 113-121.

Kilkenny, C., Browne, W.J., Cuthill, I.C., Emerson, M. \& Altman, D.G. (2010). Improving bioscience research reporting: The ARRIVE guidelines for reporting animal research. PLoS Biology 8, e1000412.

Kistler, C., Hegglin, D., Wurbel, H. \& Konig, B. (2011). Preference for structured environment in zebrafish (Danio rerio) and checker barbs (Puntius oligolepis). Applied Animal Behaviour Science 135, 318-327.

Lakra, W.S., Swaminathan, T.R. \& Joy, K.P. (2011). Development, characterisation, conservation and storage of fish cell lines. A review. Fish Physiology and Biochemistry 37, 1-20.

Lauder, G.V. (2000). Function of the caudal fin during locomotion in fishes: Kinematics, flow visualisation, and evolutionary patterns. American Zoologist 40, 101-122.

Lawrence, C. (2007). The husbandry of zebrafish (Danio rerio): A review. Aquaculture 269, $1-20$.

Lefrançois, C., Odion, M. \& Claireaux, G. (2001). An experimental and theoretical analysis of the effect of added weight on the energetics and hydrostatic function of the swimbladder of European sea bass (Dicentrarchus labrax). Marine Biology 139, 13-17.

Leips, J., Baril, C.T., Rodd, F.H., Reznick, D.N., Bashey, F., Visser, G.J. \& Travis, J. (2001). The suitability of calcein to mark poeciliid fish and a new method of detection. Transactions of the American Fisheries Society 130, 501-507.

Lewison, R., Crowder, L., Read, A. \& Freeman, S. (2004). Understanding impacts of fisheries bycatch on marine megafauna. Trends in Ecology and Evolution 19, 598-604.

Lidster, K., Readman, G.D., Prescott, M.J. \& Owen, S.F. (2017). International survey on the use and welfare of zebrafish Danio rerio in research. Journal of Fish Biology 90, 18911905.

Lim, L.C., Dhert, P. \& Sorgeloos, P. (2003). Recent developments and improvements in ornamental fish packaging systems for air transport. Aquaculture Research 34, 923-935.

Lind, J. \& Cresswell, W. (2005). Determining the fitness consequences of antipredation behaviour. Behavioral Ecology 16, 945-956.

Lopez-Luna, J., Al-Jubouri, Q., Al-Nuaimy, W. \& Sneddon, L.U. (2017a). Activity reduced by noxious chemical stimulation is ameliorated by immersion in analgesic drugs in zebrafish. Journal of Experimental Biology 220, 1451-1458.

Lopez-Luna, J., Al-Jubouri, Q., Al-Nuaimy, W. \& Sneddon, L.U. (2017b). Impact of analgesic drugs on the behavioural responses of larval zebrafish to potentially noxious temperatures. Applied Animal Behaviour Science 188, 97-105.

Lopez-Luna, J., Al-Jubouri, Q., Al-Nuaimy, W. \& Sneddon, L.U. (2017c). Impact of stress, fear and anxiety on the nociceptive responses of larval zebrafish. PLoS One 12, e0181010.

Lopez-Luna, J., Canty, M.N., Al-Jubouri, Q., Al-Nuaimy, W. \& Sneddon, L.U. (2017d). Behavioural responses of fish larvae modulated by analgesic drugs after a stress exposure. Applied Animal Behaviour Science 195, 115-120.

Love, O.P., McGowan, P.O. \& Sheriff, M.L. (2013). Maternal adversity and ecological stressors in natural populations: the role of stress axis programming in individuals, with implications for populations and communities. Functional Ecology 27, 81-92. 
Lowe, C.G., Holland, K.N. \& Wolcott, T.G. (1998). A new acoustic tailbeat transmitter for fishes. Fisheries Research 36, 275-283.

Lowe, C.G. (1996). Kinematics and critical swimming speed of juvenile scalloped hammerhead sharks. Journal of Experimental Biology 199, 2605-2610.

Lucas, M.C. (1989). Effects of implanted dummy transmitters on mortality, growth and tissue reaction in rainbow trout, Salmo gairdneri. Journal of Fish Biology 35, 577-587.

Madliger, C.L., Love, O.P., Hultine, K.R. \& Cooke, S.J. (2018). The conservation physiology toolbox: status and opportunities. Conservation Physiology 6.

Magalhaes, F.E.A., de Sousa, C.A.P.B., Santos, S.A.A.R., Menezes, R.B., Batista, F.L.A., Abreu, A.O., de Oliveira, M.V., Moura, L.F.W.G., Raposo, R.D. \& Campos, A.R. (2017). Adult zebrafish (Danio rerio): An alternative behavioral model of formalininduced nociception. Zebrafish 14, 422-429.

Makiguchi, Y. \& Ueda, H. (2009). Effects of external and surgically implanted dummy radio transmitters on mortality, swimming performance and physiological status of juvenile masu salmon Oncorhynchus masou. Journal of Fish Biology 74, 304-11.

Manire, C.A. \& Gruber, S.H. (1991). Effect of M-type dart tags on field growth of juvenile lemon sharks. Transactions of the American Fisheries Society 120, 776-780.

Malone, J.C., Forrester, G.E. \& Steele, M.A. (1999). Effects of subcutaneous microtags on the growth, survival, and vulnerability to predation of small reef fishes. Journal of Experimental Marine Biology and Ecology 237, 243-253.

Mason, G. \& Mendl, M. (1993). Why is there no simple way of measuring animal welfare? Animal Welfare 2, 301-319.

Matthews, G. \& Wickelgren W.O. (1978). Trigeminal sensory neurons of the sea lamprey. Journal of Comparative Physiology A 123, 329- 333.

Matthews, J.L. (2004). Common diseases of laboratory zebrafish. Methods in Cell Biology 77, 617-643.

Matthews, M. \& Varga, Z.M. (2012). Anesthesia and euthanasia in zebrafish. ILAR Journal 53, 192-204.

Maximino, C. (2011). Modulation of nociceptive-like behavior in zebrafish (Danio rerio) by environmental stressors. Psychology and Neuroscience 4, $149-155$

McFarlane, G.A. \& Beamish, R.I. (1990). Effect of an external tag on growth of sablefish (Anoplopoma fimbria), and consequences to mortality and age at maturity. Canadian Journal of Fisheries and Aquatic Sciences 47, 1551-1557.

McLean, D.L., Green, M., Harvey, E.S., Williams, A., Daley, R. \& Graham, K.J. (2015). Comparison of baited longlines and baited underwater cameras for assessing the composition of continental slope deepwater fish assemblages off southeast Australia. Deep Sea Research I 98, 10-20.

McVicar, A.H. (1987). Black patch necrosis of the skin of Solea solea (L.): the role of sand in prophylaxis and treatment. Journal of Fish Diseases 10, 59-63.

Mench, J.A. \& Mason, G.J. (1997). Behaviour. In Animal Welfare (Appleby, M.C. \& Hughes, B.O., eds), pp. 127-142. New York, NY: CAB International.

Merker, B.H. (2016). The line drawn on pain still holds. Animal Sentience 1(46). http://animalstudiesrepository.org/animsent/vol1/iss3/46/

Metcalfe, J.D. \& Craig, J.F. (2011). Ethical justification for the use and treatment of fishes in research: an update. Journal of Fish Biology 78, 393-394.

Methling, C., Tudorache, C., Skov, P.V. \& Steffensen, J.F. (2011). Pop up satellite tags impair swimming performance and energetics of the European eel (Anguilla anguilla). PLoS One 6, e20797. 
Mettam, J.M., Oulton, L.J., McCrohan, C.R. \& Sneddon, L.U. (2011). The efficacy of three types of analgesic drug in reducing pain in the rainbow trout, Oncorhynchus mykiss. Applied Animal Behaviour Science 133, 265-274.

Mettam J.J., McCrohan C.R. \& Sneddon L.U. (2012). Characterisation of chemosensory trigeminal receptors in the rainbow trout (Oncorhynchus mykiss): responses to irritants and carbon dioxide. Journal of Experimental Biology 215, 685-693.

Millsopp, S. \& Laming, P. (2008). Trade-offs between feeding and shock avoidance in goldfish (Carassius auratus). Applied Animal Behaviour Science 113, 247-254.

Minteer, B.A., Collins, J.P., Love, K.E. \& Puschendorf, R. (2014). Avoiding (re)extinction. Science 344, 260-261.

Mohler, J.W. (2003). Producing fluorescent marks on Atlantic salmon fin rays and scales with calcein via osmotic induction. North American Journal of Fisheries Management 23, 1108-1113.

Mommsen, T.P., Vijayan, M.M. \& Moon, T.W. (1999). Cortisol in teleosts: dynamics, mechanisms of action, and metabolic regulation. Reviews in Fish Biology and Fisheries 9, 211-268.

Montpetit, C.J. \& Perry, S.F. (1998). The effects of chronic hypoxia on the acute adrenergic stress response in the rainbow trout (Oncorhynchus mykiss). Physiological Zoology 71, 377-386.

Moore, D.R.J., Breton, R.L. \& MacDonald, D.B. (2003). A comparison of model performance for six quantitative structure-activity relationship packages that predict acute toxicity to fish. Environmental Toxicology and Chemistry 22, 1799-1809.

Nahhas, R. \& Jones, N.V. (1980). The application of the freeze-branding technique to trout fry. Aquaculture Research 11, 23-28.

Näslund, J. \& Johnson, J.I. (2014). Environmental enrichment for fish in captive environments: effects of physical structures and substrates. Fish and Fisheries 17, 1-30.

Näslund, J., Rosengren, M., Del Villar, D., Gansel, L., Norrgård, J.R., Persson, L., Winkowski, J.J. \& Kvingedal, E. (2013). Hatchery tank enrichment affects cortisol levels and shelter-seeking in Atlantic salmon (Salmo salar). Canadian Journal of Fisheries and Aquatic Sciences 70, 585-590.

Navas, J.M. \& Segner, H. (2006). Vitellogenin synthesis in primary cultures of fish liver cells as endpoint for in vitro screening of the (anti)oestrogenic activity of chemical substances. Aquatic Toxicology 80, 1-22.

Neely, B.C., Steffensen, K.D. \& Pegg, M.A. (2009). A comparison of gastrically and surgically implanted telemetry transmitters in shovelnose sturgeon. Fisheries Management and Ecology 16, 323-328.

Neiffer, D.L. \& Stamper, M.A. (2009). Fish sedation, anethesia, analgesia, and euthanasia: considerations, methods, and types of drugs. ILAR Journal 50, 343-360.

Newby, N.C., Mendonca, P.C., Gamperl, K. \& Stevens, E.D. (2006). Pharmacokinetics of morphine in fish: Winter flounder (Pseudopleuronectes americanus) and seawateracclimated rainbow trout (Oncorhynchus mykiss). Comparative Biochemistry and Physiology C 143, 275-283.

Newby, N. C., Wilkie, M. P. \& Stevens, E. D. (2009). Morphine uptake, disposition, and analgesic efficacy in the common goldfish (Carassius auratus). Canadian Journal of Zoology 87, 388-399.

Nordgreen, J., Horsberg, T.E., Ranheim, B. \& Chen, A.C.N. (2007). Somatosensory evoked potentials in the telencephalon of Atlantic salmon (Salmo salar) following galvanic stimulation of the tail. Journal of Comparative Physiology A, 193, 1235-1242.

Nordgreen, J., Garner, J.P., Janczak, A.M., Ranheim, B., Muir, W.M. \& Horsberg, T.E. (2009). Thermonociception in fish: Effects of two different doses of morphine on 
thermal threshold and post-test behaviour in goldfish (Carassius auratus). Applied Animal Behaviour Science 119, 101-107.

OATA (2015). https://ornamentalfish.org/wp-content/uploads/2015/10/CODE-OFCONDUCT-FINAL-OCT-2015.pdf

O’Brine, T.M., Vrětelová, J., Snellgrove, D.L., Davies, S.J. \& Sloman, K.A. (2015). Growth, oxygen consumption, and behavioral responses of Danio rerio to variation in dietary protein and lipid levels. Zebrafish 12, 296-304.

O'Connell, C.P. \& He, P. (2014). A large scale field analysis examining the effect of magnetically-treated baits and barriers on teleost and elasmobranch behavior. Ocean and Coastal Management 96, 130-137.

O'Shea, O.R., Mandelman, J., Talwar, B. \& Brooks, E.J. (2015). Novel observations of an opportunistic predation event by four apex predatory sharks. Marine and Freshwater Behaviour and Physiology 48, 374-380.

Oliva-Teles, A. (2012). Nutrition and health of aquaculture fish. Journal of Fish Diseases 35, 83-108.

Ottesen, O.H., Noga, E.J. \& Sandaa, W. (2007). Effect of substrate on progression and healing of skin erosions and epidermal papillomas of Atlantic halibut, Hippoglossus hippoglossus (L.). Journal of Fish Diseases 30, 43-53.

Pankhurst, N.W. (2011). The endocrinology of stress in fish: an environmental perspective. General Comparative Endocrinology 170, 265-275.

Pannevis, M.C. \& Earle, K.E. (1994). Nutrition of ornamental fish: Water soluble vitamin leaching and growth of Paracheirodon innesi. Journal of Nutrition 124, 2633S-2635S.

Paquin, P.R., Gorsuch, J.W., Apte, S., Batley, G.E., Bowles, K.C., Campbell, P.G.C., Delos, C.G., Di Toro, D.M., Dwyer, R.L., Galvez, F., Gensemer, R.W., Goss, G.G., Hogstrand, C., Janssen, C.R., McGeer, J.C., Naddy, R.B., Playle, R.C., Santore, R.C., Schneider, U., Stubblefield, W.A., Wood, C.M. \& Wu, K.B. (2002). The biotic ligand model: a historical overview. Comparative Biochemistry and Physiology 133C, 3-35.

Pham, T. M., Hagman, B., Codita, A., Van Loo, P. L. P., Strommer, L. \& Baumans, V. (2010). Housing environment influences the need for pain relief during postoperative recovery in mice. Physiology \& Behavior 99, 663-668.

Pickering, A.D., Pottinger, T.G. \& Christie, P. (1982). Recovery of the brown trout, Salmo trutta L., from acute handling stress: a time-course study. Journal of Fish Biology 20, 229-244.

Portz, D.E., Woodley, C.M. \& Cech Jr, J.J. (2006). Stress associated impacts of short-term holding on fishes. Reviews in Fish Biology and Fisheries 16, 125-170.

Pounder, K.C., Mitchell, J.L., Thomson, J., Pottinger, T., Buckley, J. \& Sneddon, L.U. (2016). Does environmental enrichment promote recovery from stress in rainbow trout? Applied Animal Behaviour Science 176, 136-142.

Raby, G.D., Packer, J.R., Danylchuk, A.J. \& Cooke, S.J. (2014). The understudied and underappreciated role of predation in the mortality of fish released from fishing gears. Fish and Fisheries 15, 489-505.

Ramstad, K.M. \& Woody, C.A. (2003). Radio tag retention and tag-related mortality among adult sockeye salmon. North American Journal of Fisheries Management 23, 978-982.

Rang, H.P., Dale, M.M., Ritter, J.M. \& Moore, P.K. (2003). Pharmacology. 797 pp. Livingstone, London: Churchill.

Readman, G.D., Owen, S.F., Murrell, J.C. \& Knowles, T.G. (2013). Do fish perceive anaesthetics as adversive? PLOS ONE 8, e73773.

Readman, G.D., Owen, S.F., Knowles, T.G. \& Murrell, J.C. (2017). Species specific anaesthetics for fish anaesthesia and euthanasia. Nature Scientific Reports 7, 7102. 
Reeves, K.S. \& Buckmeier, D.L. (2011). Mortality, predation and tag visibility of fish marked with visible implant elastomer tags. North American Journal of Fisheries Management 29, 323-328.

Reilly, S.C., Quinn, J.P., Cossins, A.R. \& Sneddon, L.U. (2008a). Novel candidate genes identified in the brain during nociception in common carp (Cyprinus carpio) and rainbow trout (Oncorhynchus mykiss). Neuroscience Letters 437, 135-138.

Reilly, S.C., Quinn, J.P., Cossins, A.R. \& Sneddon, L.U. (2008b). Behavioural analysis of a nociceptive event in fish: comparisons between three species demonstrate specific responses. Applied Animal Behaviour Science 114, 248-259.

Reinhardt, J.F., Weaver, J., Latham, P.J., Dell’Apa, A., Serafy, J.E., Browder, J.A., Christman, M., Foster, D.G. \& Blankinship, D.R. (2018). Catch rate and at-vessel mortality of circle hooks versus J-hooks in pelagic longline fisheries: A global metaanalysis. Fish and Fisheries 19, 413-430.

Ribas, L., Valdivieso, A., Díaz, N. \& Piferrer, F. (2017). Appropriate rearing density in domesticated zebrafish to avoid masculinization: links with the stress response. Journal of Experimental Biology 220, 1056-1064.

Rink, E. \& Wullimann, M.F. (2004). Connections of the ventral telencephalon (subpallium) in the zebrafish (Danio rerio). Brain Research 1011, 206-220.

Rizzo, A.L., Wooster, G.A., Guanzini, L.E., Peterson, C.M., Fenderson, K.S., Erb, H.N., Bowser, P.R. \& Martin, M.E. (2017). Biochemical, histopathologic, physiologic, and behavioral effects of nonsteroidal anti-inflammatory drugs in rainbow trout (Oncorhynchus mykiss). Comparative Medicine 67, 106-111.

Roques, J. A. C., Abbink, W., Geurds, F., van de Vis, H. \& Flik, G. (2010). Tailfin clipping, a painful procedure: studies on Nile tilapia and common carp. Physiology and Behavior 101, 533-540.

Roques, J.A.C., Abbink, W., Chereau, G., Fourneyron, A., Spanings, T., Burggraaf, D., van de Bos, R., van de Vis, H. \& Flik, G. (2012). Physiological and behavioral responses to an electrical stimulus in Mozambique tilapia (Oreochromis mossambicus). Fish Physiology and Biochemistry 38, 1019-1028.

Rose, J.D. (2002). The neurobehavioral nature of fishes and the question of awareness and pain. Reviews in Fisheries Science 10, 1-38.

Rose, J.D., Arlinghaus, R., Cooke, S.J., Diggles, B.K., Sawynok, W., Stevens, E.D. \& Wynne, C. D. L. (2014). Can fish really feel pain? Fish and Fisheries 15, 97-133.

Ross, L.J. \& Ross, B. (2008). Anaesthetic and Sedative Techniques for Aquatic Animals. Oxford: Blackwell Publishing.

Ross, M.J. \& McCormick, J.H. (1981). Effects of external radio transmitters on fish. Progress Fish-Culturist 43, 67-72.

Russell, W.M.S. \& Burch, R.L. (1959). The Principles of Humane Experimental Technique. London: Methuen.

Sampaio, F.D.F. \& Freire, C.A. (2016). An overview of stress physiology of fish transport: changes in water quality as a function of transport duration. Fish and Fisheries 17, 1055-1072.

Santana-Garcon, J., Braccini, M., Langlois, T.J., Newman, S.J., Mcauley, R.B. \& Harvey, E.S. (2014). Calibration of pelagic stereo-BRUVs and scientific longline surveys for sampling sharks. Methods in Ecology and Evolution 5, 824-833.

Santos, D., Luzio, A. \& Coimbra, A.M. (2017). Zebrafish sex differentiation and gonad development: a review on the impact of environmental factors. Aquatic Toxicology 191, 141-163.

Schaeck, M., Van den Broeck, W., Hermans, K. \& Decostere, A. (2013). Fish as research tools: alternatives to in vivo experiments. ATLA 41, 219-229. 
Schreck, C.B. (2000). Accumulation and long-term effects of stress in fish. In The Biology of Animal Stress: Basic Principles and Applications for Animal Welfare. (Moberg, G.P. \& Mench, J.A. Eds), pp. 147-158. CABI Publishing: Wallingford, U.K.

Schreck, C.B. \& Tort, L.T. (2016). The concept of stress in fish. In Biology of Stress in Fish, Fish Physiology Series, Volume 35 (Schreck, C.B., Tort, L.T., Farrell, A. \& Brauner, C., eds), pp. 1-34. New York, NY: Academic Press.

Schreck, C.B., Tort, L.T., Farrell, A. \& Brauner, C. (2016). Biology of Stress in Fish, Fish Physiology Series, Volume 35. New York, NY: Academic Press.

Schroeder, P. \& Sneddon, L.U. (2017). Exploring the efficacy of immersion analgesics in zebrafish using an integrative approach. Applied Animal Behaviour Science 187, 93102.

Séguret, A., Collignon, B. \& Halloy, J. (2016). Strain differences in the collective behaviour of zebrafish (Danio rerio) in heterogeneous environments. Royal Society Open Science 3, 160451.

Sherman, C.S., Chin, A., Heupel, M.R. \& Simpfendorfer, C.A. (2018). Are we underestimating elasmobranch abundances on baited remote underwater video systems (BRUVS) using traditional metrics? Journal of Experimental Marine Biology and Ecology 503, 80-85.

Singh, R.K., Vartak, V.R., Balange, A.K. \& Ghughuskar, M.M. (2004). Water quality management during transportation of fry of Indian major carps, Catla catla (Hamilton), Labeo rohita (Hamilton) and Cirrhinus mrigala (Hamilton). Aquaculture 235, 297-302.

Skomal, G.B., Chase, B.C. \& Prince, E.D. (2002). A comparison of circle hook and straight hook performance in recreational fisheries for juvenile Atlantic bluefin tuna. American Fisheries Society Symposium 30, 57-65.

Sloman, K.A. \& Armstrong, J.D. (2002). Physiological effects of dominance hierarchies: laboratory artefacts or natural phenomena? Journal of Fish Biology 61, 1-23.

Sloman, K.A. \& Tamilselvan, P. (2017). Developmental social experience of parents affects behaviour of offspring in zebrafish. Animal Behaviour 133, 153-160.

Sloman, K.A., McDonald, M.D., Barimo, J.F., Lepage, O., Winberg, S., Wood, C.M. \& Walsh, P.J. (2005). Does pulsatile urea excretion serve as a social signal in the Gulf toadfish Opsanus beta? Physiological and Biochemical Zoology 78, 724-735.

Sloman, K.A., Baldwin, L., McMahon, S. \& Snellgrove, D. (2011). The effects of mixedspecies assemblages on the behaviour and welfare of fish held in home aquaria. Applied Animal Behaviour Science 135, 160-168.

Small, B.C. (2003). Anaesthetic efficacy of metomidate and comparison of plasma cortisol responses to tricaine methane-sulfonate, quinaldine and clove oil anesthetised channel catfish Ictalurus punctatus. Aquaculture 218, 177-185.

Smith, A. \& Gray, H. (2011). Goldfish in a tank: the effect of substrate on foraging behaviour in aquarium fish. Animal Welfare 20, 311-319.

Smith, A.J., Clutton, R.E., Lilley, E., Hansen, K.E.A. \& Brattelid, T. (2018). PREPARE: guidelines for planning animal research and testing. Laboratory Animals 52, 135-141.

Smith, M.D., Asche, F., Guttormsen, A.G. \& Wiener, J.B. (2010). Genetically modified salmon and full impact assessment. Science 330, 1052-1053.

Smukall, M.J., Kessel, S.T., Franks, B.R., Feldheim, K.A., Guttridge, T.L. \& Gruber, S.H. (2018). No apparent negative tagging effects after 13 years at liberty for lemon shark, Negaprion brevirostris implanted with acoustic transmitter. Journal of Fish Biology in press.

Sneddon, L.U. (2002). Anatomical and electrophysiological analysis of the trigeminal nerve in a teleost fish, Oncorhynchus mykiss. Neuroscience Letters 319, 167-171. 
Sneddon, L.U. (2003a). The evidence for pain in fish: the use of morphine as an analgesic. Applied Animal Behaviour Science 83, 153-162.

Sneddon, L.U. (2003b). Trigeminal somatosensory innervation of the head of a teleost fish with particular reference to nociception. Brain Research 972, 44-52.

Sneddon, L.U. (2004). Evolution of nociception in vertebrates: comparative analysis of lower vertebrates. Brain Research Reviews 46, 123-130.

Sneddon, L.U. (2009). Pain perception in fish indicators and endpoints. ILAR Journal 50, 338-342.

Sneddon, L.U. (2011). Pain perception in fish: Evidence and implications for the use of fish. Journal of Consciousness Studies 18, 209-229.

Sneddon, L.U. (2012). Clinical anaesthesia and analgesia in fish. Journal of Exotic Pet Medicine 21, 32-43.

Sneddon L.U. (2015). Pain in aquatic animals. Journal of Experimental Biology 218, 967 976.

Sneddon, L.U., Braithwaite, V.A. \& Gentle, M.J. (2003a). Do fishes have nociceptors? Evidence for the evolution of a vertebrate sensory system. Proceedings of the Royal Society of London Series B-Biological Sciences 270, 1115-1121.

Sneddon, L.U., Braithwaite, V.A. \& Gentle, M.J. (2003b). Novel object test: Examining nociception and fear in the rainbow trout. Journal of Pain 4, 431-440.

Sneddon, L.U. Elwood, R.W, Adamo, S. \& Leach, M.C. (2014). Defining and assessing pain in animals. Animal Behaviour 97, 201-212.

Sneddon, L.U., Wolfenden, D.C.C. \& Thomson, J.S. (2016). Stress management and welfare. In Biology of Stress in Fish, Fish Physiology Series, Volume 35 (Schreck, C.B., Tort, L., Farrell, A.P. \& Brauner, C.J. eds), pp. 463-539. New York, NY: Academic Press.

Sneddon, L.U., Halsey, L.G. \& Bury, N.R. (2017). Considering aspects of the 3Rs principles within experimental animal biology. Journal of Experimental Biology 220, 3007-3016.

Sneddon, L.U. (2018). Comparative physiology of nociception and pain. Physiology 33, 6373.

Snow, P.J., Renshaw, G.M.C. \& Hamlin, K.E. (1996). Localization of enkephalin immunoreactivity in the spinal cord of the long-tailed ray Himantura fai. Journal of Comparative Neurology 367, 264-273.

Speed, C.W., O'Shea, O.R. \& Meekan, M.G. (2013). Transmitter attachment and release methods for short-term shark and stingray tracking on coral reefs. Marine Biology 160, 1041-1050.

Steinhausen, M.F., Andersen, N.G. \& Steffensen, J.F. (2006). The effect of external dummy transmitters on oxygen consumption and performance of swimming Atlantic cod. Journal of Fish Biology 69, 951-956.

Stevens, C.H., Croft, D.P., Paull, G.C. \& Tyler, C.R. (2017). Stress and welfare in ornamental fishes: what can be learned from aquaculture? Journal of Fish Biology 91, 409-428.

Stoot, L.J., Cairns, N., Cull, F., Taylor, J.J., Jeffrey, J.D., Morin, F., Mandelman, J.W., Clark, T.D. \& Cooke, S.J. (2014). Use of portable blood physiology point-of-care devices for basic and applied research on vertebrates: a review. Conservation Physiology 2 , cou011-cou011.

Strand, D.A., Utne-Palm, A.C., Jakobsen, P.J., Braithwaite, V.A., Jensen, K.H. \& Salvanes, A.G.V. (2010). Enrichment promotes learning in fish. Marine Ecology Progress Series 412, 273-282.

Stuart, K., Losordo, M., Olin, P. \& Drawbridge, M. (2013). Effects of stocking density and water conditioners on yolk-sac larvae of two marine finfish during simulated air transport. Aquaculture Research 46, 2124-2132. 
Sullivan, M., Lawrence, C. \& Blache, D. (2015). Why did the fish cross the tank? Objectively measuring the value of enrichment for captive fish. Applied Animal Behaviour Science 174, 181-188.

Sundell, K. \& Björnsson, B.T. (1988). Kinetics of calcium fluxes across the intestinal mucosa of the marine teleost, Gadus morhua, measured using an in vitro perfusion method. Journal of Experimental Biology 140, 171-186.

Sundström, L.F. \& Devlin, R.H. (2016). Ecological implications of genetically modified fishes in freshwater fisheries, with a focus on salmonids. In Freshwater Fisheries Ecology (Craig, J. F. ed.), pp. 594-615. Wiley.

Suski, C.D., Cooke, S.J., Danylchuk, A.J., O’Connor, C.M., Gravel, M.-A., Redpath, T., Hanson, K.C., Gingerich, A.J., Murchie, K.J., Danylchuk, S.E., Koppelman, J.B. \& Goldberg, T.L. (2007). Physiological disturbance and recovery dynamics of bonefish (Albula vulpes), a tropical marine fish, in response to variable exercise and exposure to air. Comparative Biochemistry and Physiology A 148, 664-73.

Sykes, P.J., Stryhn, H., Mcclure, C., Brooking, C.L., Hammell, K.L. (2012). Evaluation of external operculum loop tags to individually identify cage-cultured Atlantic halibut Hippoglossus hippoglossus in commercial research trials. Journal of Fish Biology $\mathbf{8 0}$, 2267-2280.

Talwar, B., Brooks, E., Mandelman, J. \& Grubbs, R. (2017). Stress, post-release mortality, and recovery of commonly discarded deep-sea sharks caught on longlines. Marine Ecology Progress Series 582, 147-161.

Taslima, K., Davie, A., McAndrew, B.J. \& Penman, D.J. (2016). DNA sampling from mucus in the Nile tilapia, Oreochromis niloticus: minimally invasive sampling for aquaculturerelated genetics research. Aquaculture Research 47, 4032-4037.

Taylor, J. C., Dewberry, L. S., Totsch, S. K., Yessick, L. R., DeBerry, J. J., Watts, S. A. \& Sorge, R. E. (2017). A novel zebrafish-based model of nociception. Physiology \& Behavior 174, 83-88.

Terashima, S.I. \& Liang, Y.F. (1994). C mechanical nociceptive neurons in the crotaline trigeminal ganglia. Neuroscience Letters 179, 33-36.

Thomann, R.V., Shkreli, F. \& Harrison, S. (1997). A pharmacokinetic model of cadmium in rainbow trout. Environmental Toxicology and Chemistry 16, 2268-2274.

Thorstad, E., Økland, F. \& Heggberget, T. G. (2001). Are long term negative effects from external tags underestimated? Fouling of an externally attached telemetry transmitter. Journal of Fish Biology 59, 1092-1094.

Tolentino, E.R., Howey, R.P., Howey, L.A., Jordan, L.K.B., Grubbs, R.D., Brooks, A., Williams, S., Brooks, E.J. \& Shipley, O.N. (2017). Was my science project eaten? A novel approach to validate consumption of marine biologging instruments. Animal Biotelemetry 5, 3.

Tompkins, D.M., Carver, S., Jones, M.E., Krkošek, M. \& Skerratt, L.F. (2015). Emerging infectious diseases of wildlife: a critical perspective. Trends in Parasitology 31, 149159.

Tuckey L.M. \& Smith, T.I.J. (2001). Effects of photoperiod and substrate on larval development and substrate preference of juvenile southern flounder, Paralichthys lethostigma. Journal of Applied Aquaculture 11, 1-20.

Turnbull, J.F., Bell, A., Adams, C.E., Bron, J. \& Huntingford, F.A. (2005). Stocking density and welfare of cage farmed Atlantic salmon: application of a multivariate analysis. Aquaculture 243, 121-132.

UK Farm Animal Welfare Council (2005). The Five Freedoms. Available at: http://webarchive.nationalarchives.gov.uk/20121010012427/http://www.fawc.org.uk/fr eedoms.htm 
van den Bos, R., Mes, W., Galligani, P., Heil, A., Zethof, A., Flik, G. \& Gorissen, M. (2017). Further characterisation of differences between TL and AB zebrafish (Danio rerio): Gene expression, physiology and behaviour at day 5 of the larval stage. PLoS One 12, e0175420.

Vanderzwalmen, M., Eaton, L., Mullen, C., Henriquez, F., Carey, P., Snellgrove, D. \& Sloman, K.A. (2018). The use of feed and water additives for live fish transport. Aquaculture Reviews https://doi.org/10.1111/raq.12239

von Krogh, K., Sørensen, C., Nilsson, G.E. \& Øverli, Ø. (2010). Forebrain cell proliferation, behaviour, and physiology of zebrafish, Danio rerio, kept in enriched or barren environments. Physiology \& Behavior 101, 32-39.

Wagner, G.N., Cooke, S.J., Brown, R.S. \& Deters, K.A. (2011). Surgical implantation techniques for electronic tags in fish. Reviews in Fish Biology and Fisheries 21, 71-81.

Walster, C. (2008) The welfare of ornamental fish. In Fish Welfare (Branson, E.J., ed.), pp. 269-290. Oxford: Blackwell Publishing.

Wargo Rub, A.M., Jepsen, N., Liedtke, T.L., Moser, M.L. \& Weber, E.P.S. (2014). Surgical tagging and telemetry methods in fisheries research: promoting veterinary and research collaborations. American Journal of Veterinary Research 75, 402-416.

Watanabe, T. (1982). Lipid nutrition in fish. Comparative Biochemistry and Physiology B 73, $3-15$.

Watson, J.W. \& Kerstetter, D.W. (2006). Pelagic longline fishing gear: A brief history and review of research efforts to improve selectivity. Marine Technology Society Journal 40, 6-11.

Watts, S.A., Lawrence, C., Powell, M. \& D'Abramo, L.R. (2016). The vital relationship between nutrition and health in zebrafish. Zebrafish 13, S72-S76.

Webster, M.M. \& Laland, K.N. (2009). Evaluation of a non-invasive tagging system for laboratory studies using three-spined sticklebacks Gasterosteus aculeatus. Journal of Fish Biology 75, 1868-1873.

Wells, R.M.G., McNeil, H. \& MacDonald, J.A. (2005). Fish hypnosis: Induction of an atonic immobility reflex. Marine and Freshwater Behaviour and Physiology 38, 71-78.

Wendelaar Bonga, S.E. (1997). The stress response in fish. Physiological Reviews 77, 591625.

White, G.E. \& Brown, C. (2013). Site fidelity and homing behaviour in intertidal fishes. Marine Biology 160, 1365-1372.

White, L.J., Thomson, J.S., Pounder, K.C., Coleman R.C. \& Sneddon, L.U. (2017). The impact of social context on behaviour and the recovery from welfare challenges in zebrafish, Danio rerio. Animal Behaviour 132, 189-199.

Whitmarsh, S.K., Fairweather, P.G. \& Huveneers, C. (2017). What is Big BRUVver up to? Methods and uses of baited underwater video. Reviews in Fish Biology and Fisheries 27, 53-73.

Whitmore, B.M., White, C.F., Gleiss, A.C. \& Whitney, N.M. (2016). A float-release package for recovering data-loggers from wild sharks. Journal of Experimental Marine Biology and Ecology 475, 49-53.

Wilkes, L., Owen, S.F., Readman, G.D., Sloman, K.A. \& Wilson, R.W. (2012). Does structural enrichment for toxicology studies improve zebrafish welfare? Applied Animal Behaviour Science 139, 143-150.

Williams, T.D., Readman, G.D. \& Owen, S.F. (2009). Key issues concerning environmental enrichment for laboratory-held fish species. Laboratory Animals 43, 107-120.

Wilson, S.M., Raby, G.D., Burnett, N.J., Hinch, S.G. \& Cooke, S.J. (2014). Looking beyond the mortality of bycatch: sublethal effects of incidental capture on marine animals. Biological Conservation 171, 61-72. 
Wilson, R.P., Holton, M., Wilson, V.L., Gunner, R., Tysse, B., Wilson, G.I., Quintana, F., Duarte, C. \& Scantlebury, D.M. (2018). Towards informed metrics for examining the role of human-induced animal responses in tag studies on wild animals. Integrated Zoology 10, 267-281.

Wolf, K. \& Quimby, M.C. (1962). Established eurythermic line of fish cells in vitro. Science 135, 1065-1066.

Wong, D., von Keyserlingk, M.A.G., Richards, J.G. \& Weary, D.M. (2014). Conditioned place avoidance of zebrafish (Danio rerio) to three chemicals used for euthanasia and anaesthesia. PLOS ONE 9, e88030.

Wood, C.M. (1991). Acid-base and ion balance, metabolism, and their interactions, after exhaustive exercise in fish. Journal of Experimental Biology 160, 285-308.

Wood, C.M., Turner, J.D. \& Graham, M.S. (1983). Why do fish die after severe exercise? Journal of Fish Biology 22, 189-201.

Wood, C.M., Kelly, S.P., Zhou, B., Fletcher, M., O’Donnell, M., Elettib, B. \& Pärt, P. (2002). Cultured gill epithelia as models for the freshwater fish gill. Biochimica et Biophysica Acta 1566, 72-83.

Wright, P.A. \& Wood, C.M. (2012). Seven things fish know about ammonia and we don't. Respiratory Physiology and Neurobiology 184, 231-240.

Yang, S.D., Liou, C.H. \& Liu, F.G. (2002). Effects of dietary protein level on growth performance, carcass composition and ammonia excretion in juvenile silver perch (Bidyanus bidyanus). Aquaculture 213, 363-372.

Yoshida, M. \& Hirano, R. (2010). Effects of local anesthesia of the cerebellum on classical fear conditioning in goldfish. Behavioral Brain Function 6, 20.

Young R.F. (1977). Fiber spectrum of the trigeminal sensory root of frog, cat and man determined by electron microscopy. In: Pain in the Trigeminal Region (Anderson, D.L. \& Matthews, D., eds), 137-160 pp. Amsterdam: Elsevier. 
Table 1. The three classes of analgesic drugs tested in fishes, documenting the range of doses investigated, the species employed in the study, side effects including whether the analgesic prevented changes related to noxious stimuli and a comment on analgesic efficacy (based on data from Curtwright et al., 2015; Davis et al., 2006; Harms et al., 2005; Lopez-Luna et al., 2017a; Mettam et al., 2011; Newby et al., 2006; 2009; Nordgreen et al., 2009; Rizzo et al., 2017; Schroeder \& Sneddon, 2017; Sneddon, 2003b; Taylor et al., 2017). Where not effective is stated these drugs did not prevent the changes in behaviour associated with treatment with a noxious stimulus. The drugs were administered by injection at the site of damage, intramuscularly (i.m.), intraperitoneally (i.p.) or via immersion in tank water.

\begin{tabular}{|c|c|c|c|c|}
\hline Analgesic & Dose & Species & Side effects & Efficacy \\
\hline \multicolumn{5}{|c|}{ Local Anaesthetics } \\
\hline \multirow[t]{2}{*}{ Lidocaine } & $0.1-2 \mathrm{mg}$ & Trout (at site) & None observed & Injection at $1 \mathrm{mg}$ \\
\hline & $1-5 \mathrm{mg} \mathrm{l}^{-1}$ & Zebrafish (immersion) & None observed & Immersion at $2.5-5 \mathrm{mg} \mathrm{l}^{-1}$ \\
\hline \multicolumn{5}{|l|}{ Opioids } \\
\hline \multirow[t]{4}{*}{ Morphine } & $2.5-50 \mathrm{mg} \mathrm{kg}^{-1}$ & Trout (i.m.) & None observed & i.m. at $5 \mathrm{mg} \mathrm{kg}^{-1}$ \\
\hline & & Flounder (i.p.) & & \\
\hline & & Goldfish (i.m.) & & \\
\hline & & Koi carp (i.m.) & & \\
\hline
\end{tabular}




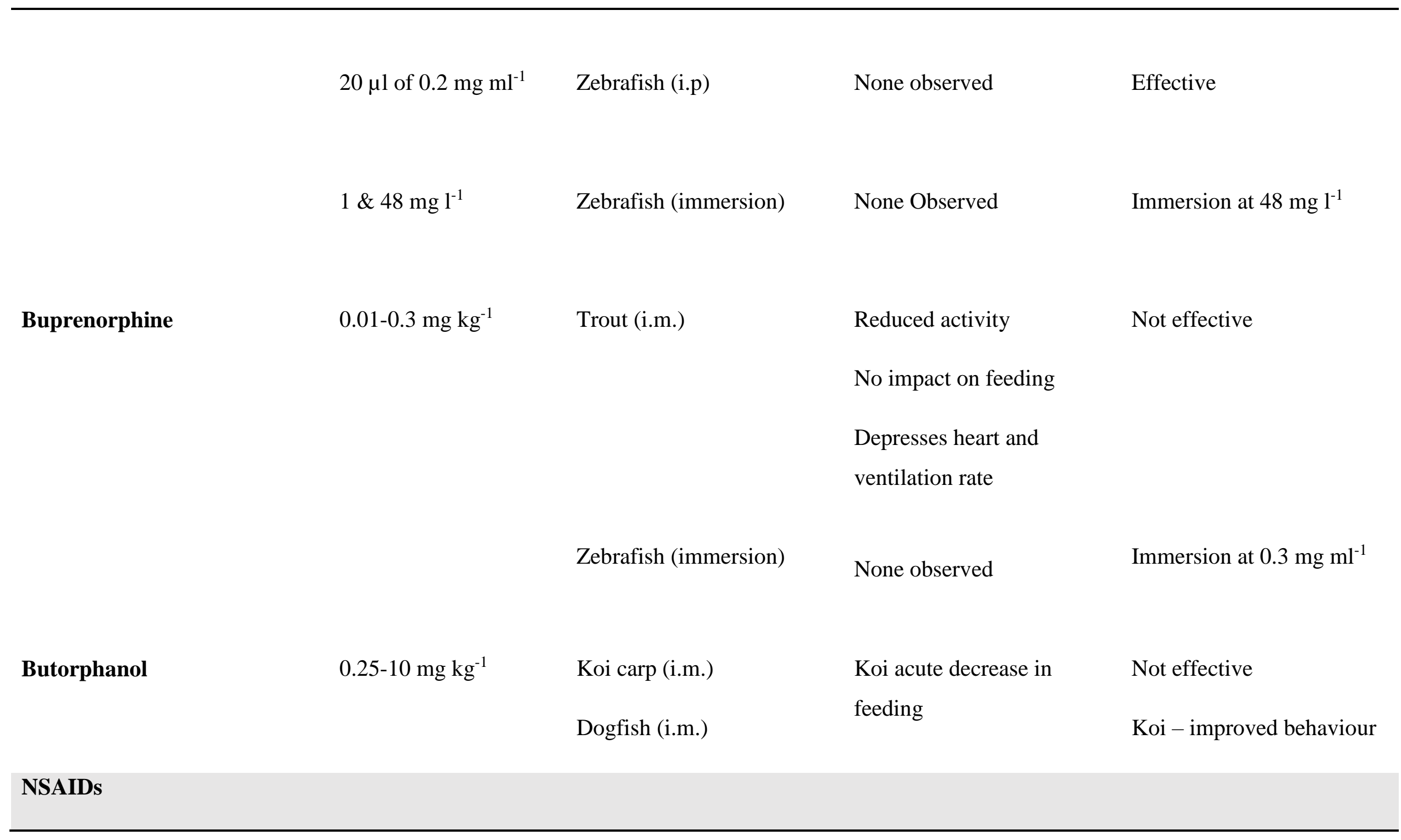




\begin{tabular}{|c|c|c|c|c|}
\hline Carprofen & $1-5 \mathrm{mg} \mathrm{kg}^{-1}$ & Trout (i.m.) & $\begin{array}{l}\text { Depressed activity } \\
\text { Increased ventilation }\end{array}$ & $\begin{array}{l}\text { Reduced suspension of } \\
\text { feeding using } 2.5 \mathrm{mg} \mathrm{kg}^{-1}\end{array}$ \\
\hline \multirow[t]{3}{*}{ Ketoprofen } & $1-4 \mathrm{mg} \mathrm{kg}^{-1}$ & Koi carp (i.m.) & No impact on behaviour in & Not effective \\
\hline & & Dogfish (i.m.) & Koi and trout & \\
\hline & & Trout (i.m.) & $\begin{array}{l}\text { Healing and physiology } \\
\text { unaffected in trout }\end{array}$ & \\
\hline Aspirin & $1-2.5 \mathrm{mg} \mathrm{l}^{-1}$ & Zebrafish (Immersion) & None observed & Immersion at $2.5 \mathrm{mg} \mathrm{l}^{-1}$ \\
\hline Ketorolac & $0.5 \mathrm{mg} \mathrm{kg}^{-1}$ & Trout (i.m.) & $\begin{array}{l}\text { No impact on behaviour, } \\
\text { physiology or healing }\end{array}$ & Not effective \\
\hline Flunixin & $0.5 \mathrm{mg} \mathrm{kg}^{-1}$ & Trout (i.m.) & $\begin{array}{l}\text { No impact on behaviour, } \\
\text { physiology or healing }\end{array}$ & Not effective \\
\hline Indomethacin & $20 \mu \mathrm{l}$ of $0.2 \mathrm{mg} \mathrm{ml}^{-1}$ & Zebrafish (i.p.) & None observed & Effective \\
\hline
\end{tabular}




\section{Scientific Procedure}

Fin Clipping

\section{Ethical considerations}

Fin clipping is a common technique used to acquire a DNA sample, where a small portion of the fin is removed, usually the caudal fin. Fin clipping is carried out in a variety of species, including small species such as zebrafish and three-spined stickleback Gasterosteus aculeatus L. 1758 where the 'clip' may represent quite a large proportion of the fin. Fin clipping is usually carried out under anaesthesia, but can potentially cause pain and the use of an additional analgesic has been recommended (Schroeder \& Sneddon, 2017). The importance of the caudal fin for fish locomotion is well documented (Lauder, 2000) and caudal amputation has significant consequences for swimming efficiency (Fu et al., 2013). While there is evidence in some species that fin clipping does not affect behaviour (e.g. Champagne et al., 2008), it has been suggested that fin clipping can compromise scientific results through secondary infections and changes in behaviours involving fins (Breacker et al., 2017). A technique of skin swabbing to obtain a DNA sample has been used in larger fishes (Campanella \& Smalley, 2006; Taslima et al., 2016) and recently validated as a noninvasive alternative to obtain DNA in zebrafish and stickleback (Breacker et al., 2017) with significant ethical implications. The removal of the adipose fin in salmonids is a common procedure used particularly for distinguishing between hatchery-reared and wild fishes. The adipose fin lacks musculature and skeletal structures; however, its assumed vestigial role has recently been challenged with evidence of extensive nervous tissue and mechanosensory function (Buckland-Nicks et al. 2012; Aiello et al. 2016; Buckland-Nicks, 2016). 
anaesthesia for more minor surgeries is debated (Cooke et al., 2016a). Major surgery usually refers to the penetration of the body cavity, or surgery that will cause significant physiological or physical disturbance to the fish (AFS, 2014). In particular, surgery methods for the implantation of electronic tags have been reviewed (Wagner et al., 2011) with surgeon training and experience playing an important role in influencing surgical success (Deters $e t$ al., 2010). Post-operative care is also a crucial part of the surgical procedure (Cooke et al., 2016a). Individuals should be carefully monitored to ensure there are no unintended effects of surgery, which would lead to the need for euthanasia. potentially deleterious compounds or organisms. Such studies may include lethal endpoints, however, in some countries legislation requires full justification to explain why lethal endpoints are necessary and clear evidence that the objectives cannot be achieved by any other means. Nevertheless, the fish acute median lethality test (LC50) is still widely used for testing the toxicity of novel compounds (Schaeck et al., 2013). The application of deleterious conditions that may result in suffering or mortality need to be monitored frequently (ASAB, 2012, 2018). Within toxicity testing, there has been a clear move away from the use of adult fishes towards the use of embryos as a form of partial replacement (Schaeck et al., 2013), however, some caution is required in relation to ethical interpretation with emerging evidence that larval fishes respond to noxious stimuli (Lopez-Luna et al., 2017a). 


\begin{tabular}{|c|c|}
\hline Blood sampling & $\begin{array}{l}\text { Non-terminal blood samples are usually taken from the caudal vein running beneath the } \\
\text { vertebrae (Bennett et al., 2016) using a needle diameter and syringe size suitable for the size } \\
\text { of fish. Needles should be sharp to ensure clean entrance to the vein and anti-coagulants are } \\
\text { often used to stop clotting in the collection vessel. For small fishes, non-terminal blood } \\
\text { sampling is not possible; caudal severance to allow collection of blood by capillary action } \\
\text { can be combined with euthanasia. Other methods of blood sampling such as cardiac puncture } \\
\text { are more invasive and can affect survival. }\end{array}$ \\
\hline Intra or Interspecific Aggression & $\begin{array}{l}\text { Competition studies involving the formation of dominance hierarchies or escalated fighting } \\
\text { may elicit physiological consequences (Sloman \& Armstrong, 2002). Injury can be } \\
\text { minimised by the provision of shelters and continuous monitoring so that opponents can be } \\
\text { removed as soon as contests are complete. Mirror image tests have been used as an } \\
\text { alternative to dyadic encounters (Sloman \& Tamilselvan, 2017) and while there are } \\
\text { circumstances when they may not provide all the information required for the experimental } \\
\text { objectives there are many instances where they are an acceptable alternative (Balzarini et al., } \\
2014 \text {; Elwood et al., 2014). The main advantage of the mirror image test is that it removes } \\
\text { the potential for physical injury. }\end{array}$ \\
\hline Predation Studies (where fishes are prey) & $\begin{array}{l}\text { In their natural environment, fishes usually eat other fishes and of course they will eat them } \\
\text { alive. However, when feeding live fishes to live fishes in a captive environment, we need to } \\
\text { consider the welfare of both the predator and the prey (Metcalfe \& Craig, 2011). Often the } \\
\text { predator is the focus of the study and so welfare is adequately considered but the welfare of } \\
\text { the prey fish is ignored. In the wild a prey fish is likely to have a much greater chance of }\end{array}$ \\
\hline
\end{tabular}


escape, compared to predation in a bare tank without refuge. In a barren environment where prey is confined in close contact with the predator, the environmental relevance of the situation must be considered and consequences for results (Lind \& Cresswell, 2005). For example, a toxicant may be found have an impact on a fish's ability to catch another fish in a tank environment, but such an experiment tells us next to nothing about the ability of an exposed fish to catch another fish in a natural situation. Close confinement with a predator inevitably will induce a stress response in the prey prior to and during the predation event (Hart, 1997). Mesocosm experiments may reduce stress and may overcome some of the problems associated with the interpretation of simple laboratory studies. Many fishes swallow their prey whole (Gill, 2003), and it could be argued that a predation event by an efficient predator is quick with minimal suffering. Additionally, some fishes will not eat anything other than live food thus the welfare of the predator becomes a necessary consideration. Where predation of live fishes is deemed the only method, and the scientific advancement is justified, continuous observation with intervention to cull any injured prey during failed predation attempts is recommended (ASAB, 2012, 2018).

Genetic Modification Studies which alter the genetic material of a fish are prevalent in the zebrafish and medaka literature. There is also a significant literature surrounding the genetic modification of salmonids (Sundström \& Devlin, 2016). Ethical considerations include whether the modified phenotype is detrimental to the welfare of the individual (ASAB, 2012, 2018), and the risk to humans and the wider environment if they escape captivity (Smith et al., 2010). 
